\title{
A Review on Characterizations and Biocompatibility of Functionalized Carbon Nanotubes in Drug Delivery Design
}

\author{
Julia M. Tan, ${ }^{1}$ Palanisamy Arulselvan, ${ }^{2}$ Sharida Fakurazi, ${ }^{2,3}$ \\ Hairuszah Ithnin, ${ }^{4}$ and Mohd Zobir Hussein ${ }^{1}$ \\ ${ }^{1}$ Materials Synthesis and Characterization Laboratory, Institute of Advanced Technology, Universiti Putra Malaysia (UPM), \\ 43400 Serdang, Selangor, Malaysia \\ ${ }^{2}$ Laboratory of Vaccine and Immunotherapeutics, Institute of Bioscience, Universiti Putra Malaysia (UPM), 43400 Serdang, \\ Selangor, Malaysia \\ ${ }^{3}$ Department of Human Anatomy, Faculty of Medicine and Health Sciences, Universiti Putra Malaysia (UPM), \\ 43400 Serdang, Selangor, Malaysia \\ ${ }^{4}$ Department of Pathology, Faculty of Medicine and Health Sciences, Universiti Putra Malaysia (UPM), 43400 Serdang, \\ Selangor, Malaysia
}

Correspondence should be addressed to Mohd Zobir Hussein; mzobir@upm.edu.my

Received 6 January 2014; Revised 16 April 2014; Accepted 17 April 2014; Published 15 July 2014

Academic Editor: Enrico Bergamaschi

Copyright (C) 2014 Julia M. Tan et al. This is an open access article distributed under the Creative Commons Attribution License, which permits unrestricted use, distribution, and reproduction in any medium, provided the original work is properly cited.

The revolutionary development of functionalized carbon nanotubes ( $f$-CNTs) for applications in nanomedicine has emerged as one of the most interesting fields, which has increased exponentially in recent years. This is due to their appealing physical and chemical properties, as well as their unique architecture. After a brief introduction on the physicochemical properties of carbon nanotubes (CNTs), we described several functionalization methods for the surface modification of CNTs, with the aim to facilitate their solubility in physiological aqueous environment. This review focuses on recent advances in drug delivery design based on $f$ CNTs with an emphasis on the determination of various parameters involved and characterization methods used in order to achieve higher therapeutic efficacy of targeted drug delivery. In particular, we will highlight a variety of different analytical techniques which can be used to characterize the elemental composition, chemical structure, and functional groups introduced onto the CNTs after surface modification. We also review the current progress of available in vitro biocompatibility assays based on $f$-CNTs and then discuss their toxicological profile and biodistribution for advanced drug delivery.

\section{Introduction}

In the past few decades, carbon nanotubes (CNTs) have received tremendous attention from the science community for fundamental research as well as their applications in various fields of study such as catalyst supports [1], hydrogen storage medium [2], field emission displays [3], composite materials [4], sensors and biosensors [5], nanoprobes and, most recently, as a potential drug delivery vehicle for therapeutics agents [6] in nanomedicine. The term "nanomedicine" is a new technology combining the use of both traditional medical technology and nanotechnology where nanosizeengineered materials of less than $100 \mathrm{~nm}$ size regime are employed. This interdisciplinary technology covers a wide range of therapeutic applications, from nanoparticulate drug delivery systems (e.g., carbon nanotubes, layered double hydroxides [7-12]), to in vitro (e.g., biosensor) and in vivo (e.g., imaging and implantable devices) diagnostics. The intentions of using nanomedicine in drug delivery applications are to achieve (1) improved delivery of water insoluble drugs [13]; (2) delivery of large macromolecule drugs to intracellular sites of action; (3) codelivery of two or more drugs or therapeutic agents for combination treatment; (4) transcytosis of drugs across tight epithelial and endothelial barriers [14]; (5) targeted delivery of drugs in a cell- or tissue-specific manner; (6) real-time read on the in vivo 
efficacy of a therapeutic agent, and (7) visualization of sites of drug delivery by combining therapeutic agents with imaging probes [15].

Since the discovery of CNTs in the early 1990s $[16,17]$, the revolutionary development of these nanotubes for the applications of nanomedicine has emerged as one of the most interesting fields, which has increased exponentially in recent years. CNTs are attractive due to their appealing features such as rich electronic and thermal properties, good mechanical strength, extremely great chemical stability, ultralight weight, high aspect ratio, and high surface area [18]. In fact, these innovative carriers exhibit little cytotoxicity, capable of immobilizing therapeutic agents (e.g., drugs, proteins, DNA, antibodies) on the outer wall $[19,20]$ or by encapsulation inside the nanotubes [21]. Due to their nanoneedle-like structure, they were found to be taken up efficiently by cells [22] and to translocate directly into the cytoplasm of target cells without causing cell death [23].

Basically, CNTs are long, tubular fullerene structures in which the walls of the CNTs comprise of hexagonal carbon and the end tips are pentagonal rings [4]. These nanotubes can be either single-walled (SWCNTs) or multiwalled (MWCNTs), and they are highly ordered, pseudoone-dimensional carbon allotropes. SWCNTs comprise of a rolled-up single layer of graphite cylinder with a tube diameter of $0.4-2 \mathrm{~nm}$, whereas MWCNTs are multiple concentric cylindrical shells of graphite sheets with interlayer distance of approximately $0.36 \mathrm{~nm}$ with diameters of 2$100 \mathrm{~nm}$ (Figure 1). Both nanotubes are synthesized by different approaches, such as carbon arc discharge [27], chemical vapour deposition [28], pyrolysis, and laser ablation method [29]. Among these methods, laser ablation is one of the superior ways to produce CNTs with high purity and high quality. Even though there have been major advances in the production of CNTs, they are still relatively costly especially SWCNTs, due to their uses in lower quantity output but higher value technologies.

\section{Functionalization of Carbon Nanotubes}

There has been significant progress in the research of $f$ CNTs for the advanced delivery of drugs and biomolecules in nanomedicine. Even though CNTs possessed excellent chemical and physical properties, pristine (nonfunctionalized) CNTs usually contain impurities such as catalyst nanoparticles and amorphous carbon. They are intrinsically waterinsoluble and cannot disperse uniformly in most aqueous media due to their hydrophobic structure. This has posed a major technical barrier and health concern for biocompatibility evaluation towards drug delivery applications. Therefore, CNTs need to be purified and soluble in physiological environment prior to be used as drug carriers in nanomedicine. There are various methods used to purify CNTs and the most commonly used methods involve oxidative acid treatment, like refluxing/sonication in a concentrated $\mathrm{H}_{2} \mathrm{SO}_{4} / \mathrm{HNO}_{3}$ mixture [30] for the removal of residual metal catalysts. In order to improve their solubility and biocompatibility level, covalent or noncovalent chemical functionalization can be used to obtain soluble conjugates.
2.1. Covalent Functionalization. The covalent functionalization is more advantageous than noncovalent functionalization if a strong bond is required between the nanotubes and the biomolecules. This covalent binding relies very much on the grafting of chemically reactive molecules onto their inert $\mathrm{sp}^{2}$ carbon structure of the $\pi$-conjugated skeleton, which can only be achieved by direct functionalization of pristine CNTs with hydrophilic polymers such as polyethylene glycol (PEG), oligomers, or biomolecules via defect or sidewall functionalization of the CNTs. However, this method can result in a loss of material during the acid oxidation process and a partial loss of optical properties and electronic structure of the CNTs. Generally, these issues are of less importance in the applications of drug delivery [31].

Purification techniques such as acid oxidation modify CNTs surfaces by inducing the opening of the tube caps and formation of holes at the sidewalls resulting in CNTs with tips and sidewalls decorated with oxygenated functionalities (e.g., carboxylic, carbonyl, and hydroxyl groups). Carboxylic acid functionality is the most commonly used surface defectderived moieties to connect CNTs with amines site on the biomolecules [32]. The carboxylic acids are first activated by crosslinking agents, such as carbodiimides [33], active esters [34], thionyl, or oxalyl chloride [35] to obtain highly reactive intermediates, yielding ester or amide linkages, and subsequently used to covalently attach to various types of biomolecules. Other approaches such as fluorination by elemental fluorine, hydrogenation, radical additions, ozonolysis, electrophilic addition, and 1,3-dipolar cycloaddition of azomethine yields were found to be successful for sidewall covalent functionalization reactions of CNTs.

2.2. Noncovalent Functionalization. Noncovalent functionalization is not destructive to the $\mathrm{sp}^{2}$ bonding compared to covalent functionalization and, therefore, preserves the functional properties and native structure of CNTs more effectively than covalent methods. The functionalization mechanisms for the noncovalent dispersion of CNTs are often straightforward with the use of sonication, mixing, mixing followed by sonication, centrifugation, or filtration. Nevertheless, the chemical interactions of noncovalent approaches may still incur significant surface doping effects in the nanotubes due to the electronic transitions [36]. Besides, noncovalent bond is susceptible to environmental factors, like salt concentration and $\mathrm{pH}$ and is generally less stable [37].

Pristine CNTs are very difficult to disperse in solution due to the formation of big bundles held strongly together by the van der Waals forces. In order to separate the nanotubes from self-aggregation, various dispersion agents such as ioniccomplementary peptides [38], biomolecules [39], surfactants [40], pyrene-containing polymers [41], and hyaluronic acid [42] as well as other natural polymers like gum Arabic, amylose, and Suwannee River natural organic matter [43] are used in order to achieve the desired dispersion effect.

An in-depth study on the surface modifications by covalent and noncovalent method for the effective dispersion of CNTs is extensively reviewed by Kim et al. [44]. Not only have they provided useful guidelines for the preparation of effective dispersions of CNTs in solvents and polymers, 

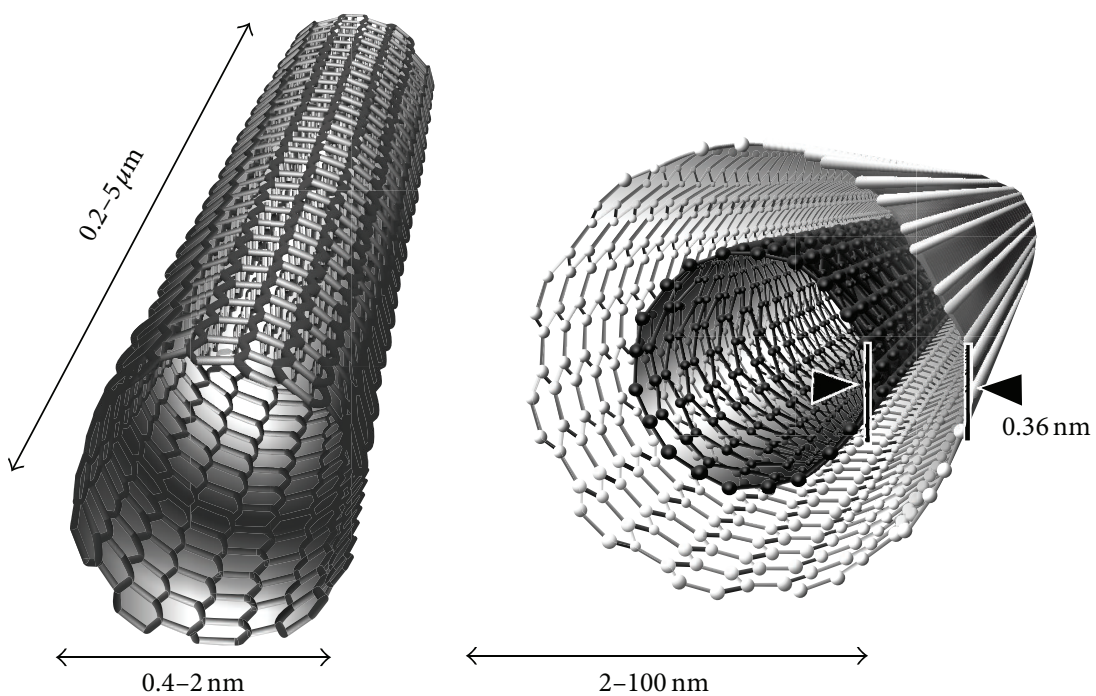

FIGURE 1: Carbon nanotubes: single-walled carbon nanotubes (SWCNTs) on the left; and multiwalled carbon nanotubes (MWCNTs) on the right. Adapted from $[24,25]$. This research was originally published in [26] @ by the Society of Nuclear Medicine and Molecular Imaging, Inc.

but also they have highlighted several issues concerning the quantitative characterization of surface modifications and effective dispersions of CNTs. In view of the vast number of papers published on the context of chemical functionalization and surface modifications of CNTs, we attempt to highlight only the recent development of $f$-CNTs conjugated with bioactive agents carried out from the year of 2010 up till date. Table 1 summarizes the development of both covalent and noncovalent functionalization of CNTs for delivery of drugs, biomolecules, and/or imaging agents in nanomedicine.

\section{Design of Carbon Nanotube-Mediated Delivery Systems in Therapeutics}

Prior to designing a novel delivery system, there are several critical parameters which need to be taken into consideration for the preparation of a functional targeted drug delivery and this will be discussed in the section below.

\subsection{Determination of Parameters in a Delivery Mechanism}

3.1.1. Physical Form. For an effective delivery, the administered delivery system must be adsorbed and distributed, reach the targeted site, and then react with the desired tissue and exert a response. The uptake and biodistribution of a delivery system is heavily dependent upon its physical properties such as length, diameter, shape, size, and aggregation [68].

In the case of CNTs, if the length of the tubes is more than $15 \mu \mathrm{m}$, which is the diameter of a phagocytic cell, it becomes difficult for the macrophages to phagocytose it [69]. As a result, inflammation occurs which may lead to fibrosis. There are a few studies which indicated that shorter CNTs (0.1-0.2 $\mu \mathrm{m}$ in length) were easily phagocytosed and excreted by the kidney [70], whereas longer CNTs $(15-30 \mu \mathrm{m})$ were not found in macrophages and resulted in the triggered release of inflammatory mediators [69]. Besides, CNTs with differing sizes ( $<8 \mathrm{~nm}, 20-30 \mathrm{~nm},>50 \mathrm{~nm}$; but of the same length $0.5-2 \mu \mathrm{m})$ had different effects and characteristics in cellular uptake, cell viability, and intracellular responses as well as potential mechanisms of toxicity, depending on the exposed cell type [71]. Hence, one can easily tailor the properties of the CNTs by specifically choosing the desired features (length, diameter, shape, and size) to suit different drug delivery applications.

3.1.2. Surface Chemistry. Surface modification of pristine CNTs by either covalent or noncovalent surface functionalization will increase the solubility of CNTs and, hence, renders them more biocompatible in physiological aqueous environment. This is because the delivery system is administered into the human body and highly hydrophobic pristine CNTs may cause aggregation which further leads to characteristic cell changes and death (apoptosis) [31].

In line with this, several groups of researchers carried out in vitro experiments using various types of $f$-CNTs with different surface charges (positive, negative, or neutral) [22, 72]. They demonstrated that cells did not exhibit apoptosis/necrosis and $f$-CNTs were intracellularly taken up by cells as evident by techniques such as confocal microscopy, fluorescence-activated cell sorting, and protocols. Thus, it is expected that the cytotoxicity of cells is decreased with the increase in the degree of functionalization of the CNTs. Moreover, the aggregation of individual tubes which are held strongly together by van der Waals forces is also significantly reduced by the surface functionalization.

In addition to that, there were also reports which indicated that the size of the functional group (molecular weight $>60 \mathrm{kDa}$ ) may cause toxicity in cells $[73,74]$. Furthermore, the medium-sized $(<80 \mathrm{kDa})$ protein-CNT conjugates was observed to be efficiently taken up by cells, whereas the intracellular transport of large conjugates yields lower levels of uptake. 


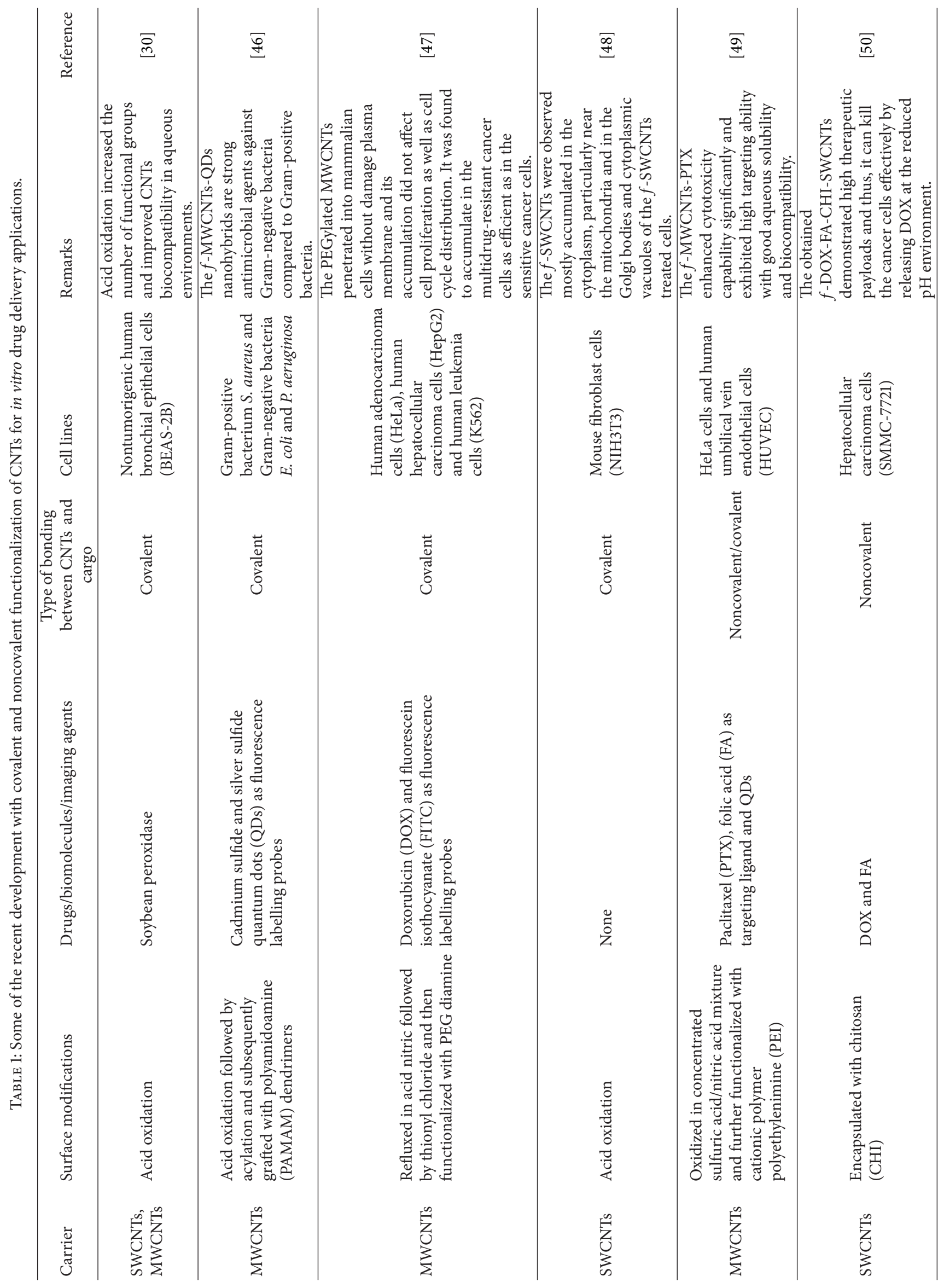




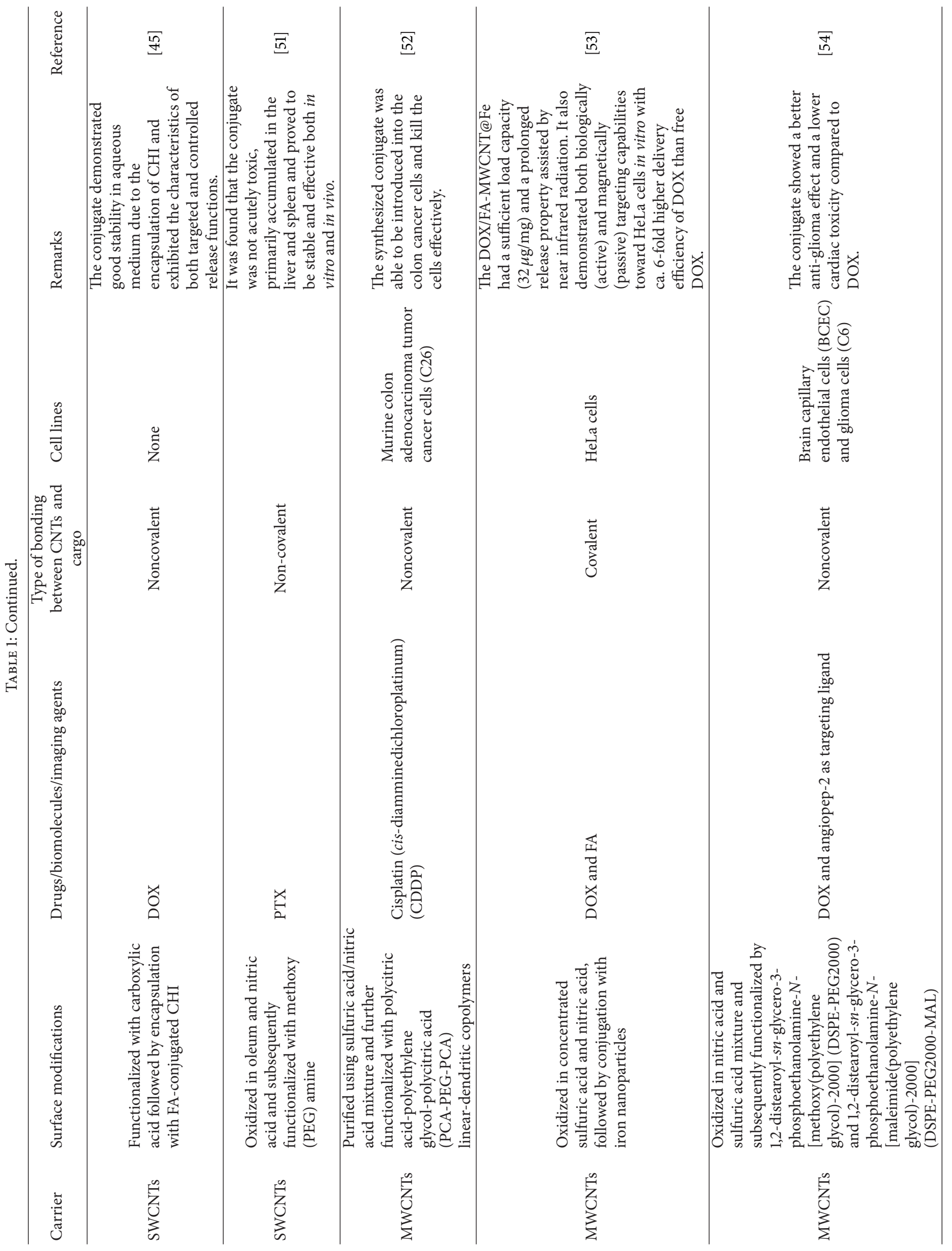




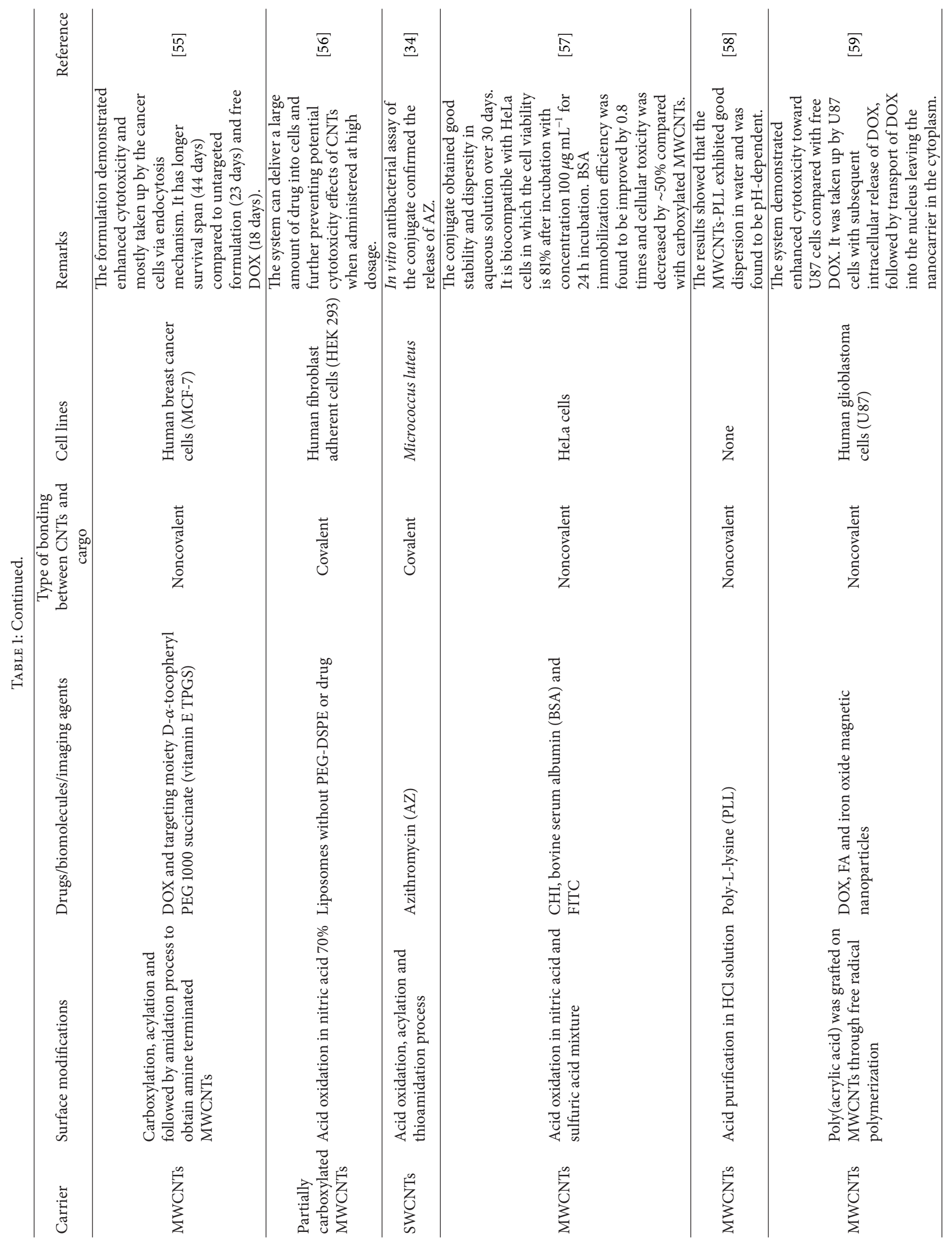




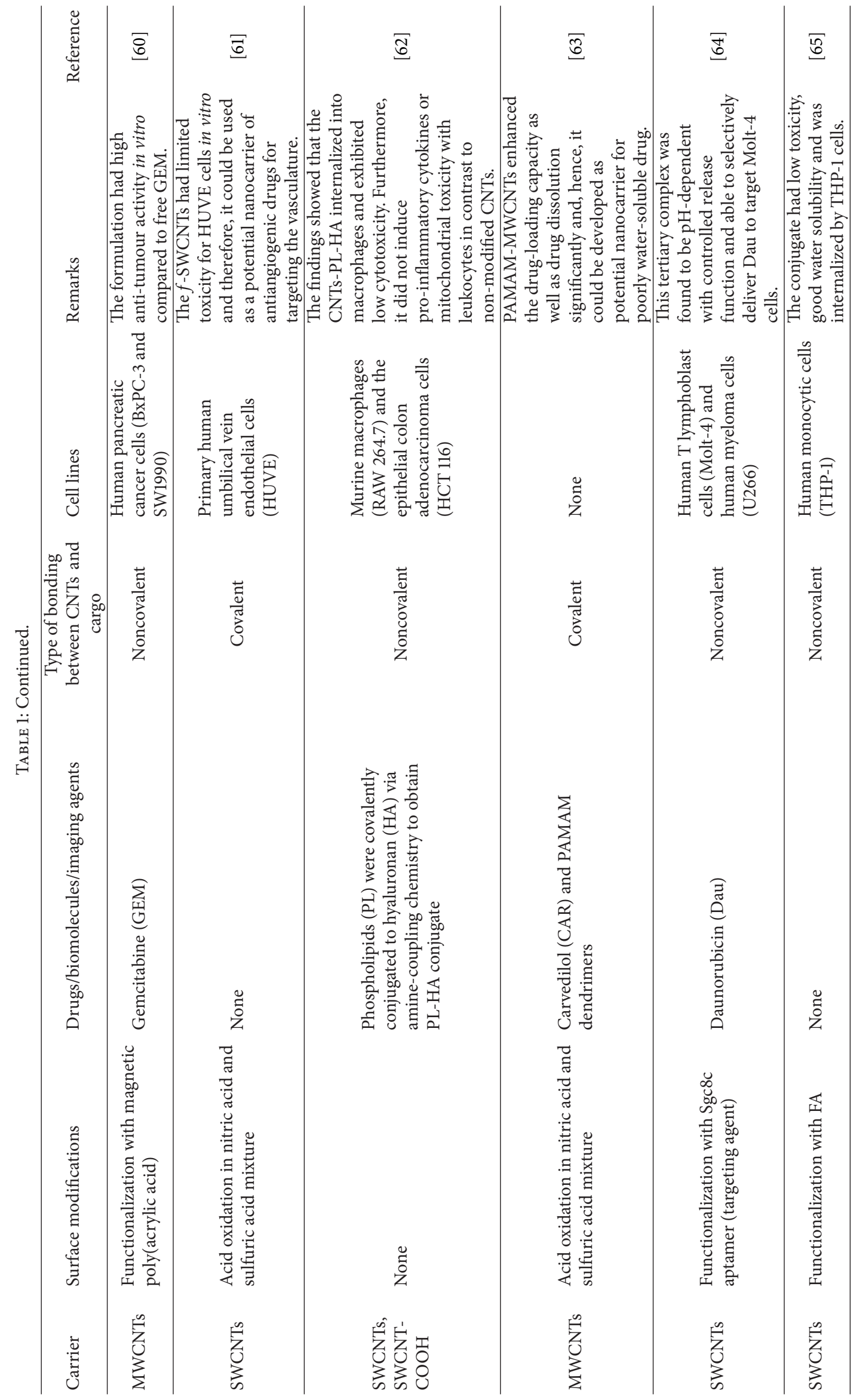


3.1.3. Degree of Purification. During the fabrication of CNTs, organic materials such as amorphous carbon, extrinsic defects like catalyst residue ( $\mathrm{Fe}, \mathrm{Ni}$, and $\mathrm{Co}$ ), or supporting materials (typically silica, alumina, or magnesium oxide) embedded in the nanotubes could be harmful to biomedical applications. These transition metals can interact and catalyse oxidative species in cells through free radical generation, causing oxidative stress and morphological changes to the cellular structures [75].

In order to identify the issue related with impurities within the CNTs, a group of researchers have conducted a systemic study of immunological responses in mice by using iron-contaminated and extremely pure MWCNTs [76]. They found that the as-grown nanotubes (contaminated MWCNTs) subcutaneously implanted in the mice give rise to acute toxicity resulting in severe hair loss and inflammation, whereas the extremely clean nanotubes demonstrated good biocompatibility. In a related context, neurological impacts of MWCNTs with different concentrations of iron impurities (3\% and 23\%) were investigated on rat pheochromocytoma cell line [77]. The authors observed that the highest content of iron in the CNTs can increase cytoskeletal disruption, reduce cells viability, and diminish the ability to form mature neurites in the neural cells. Therefore, it is very crucial to purify the CNTs prior to use in biomedical research for drug delivery therapy as the impurities strapped inside the CNTs may be the main cause of toxicity.

3.1.4. Dose- and Time-Dependent Exposure. It is generally believed that the CNTs nanocarriers are dose- and timedependent in many in vitro $[55,61,70]$ experiments carried out in the past years. This wide range of values rely heavily on the types of CNTs used, experimental methods of functionalization and the bioactive compound adopted in the conjugation process. An extensive compilation of cell viability studies on different types and concentrations of $f$ CNTs is listed elsewhere in the literature [74] and only a few representative results will be discussed here.

A group of researchers performed an in vitro cytotoxicity evaluation of carboxylated SWCNTs on differentiated (cultured and grown for 21 days) and nondifferentiated (maintained as monolayer model) Caco- 2 cells, a human intestinal carcinoma cell line [78]. Caco-2 cells were differentiated under specific condition in order to compare the sensitivity of the cells to $f$-SWCNTs. A concentration ranging from 5 to $1000 \mu \mathrm{g} / \mathrm{mL}$ was used being that the gastrointestinal tract is also one of the possible routes of CNTs exposure besides dermal, inhalation, and injection for direct interactions with nanomaterials. The results showed a dose-dependent trend and toxic effects were found to be induced in both differentiated and nondifferentiated Caco cells at concentrations higher than $100 \mu \mathrm{g} / \mathrm{mL}$ with differentiated cultures showing a higher sensitivity.

On the other hand, Patlolla et al. investigated the cytotoxicity of oxidized MWCNTs in normal human dermal fibroblast cells, which would be among the first exposed cell types that these engineered nanomaterials can enter the human vascular system through open wounds [79]. The cell viability and proliferation assay revealed that the CNTs is dose and time-dependent with inhibitory response induced at the highest dose of MWCNTs $(400 \mu \mathrm{g} / \mathrm{mL}$ ) (equals $10 \mathrm{ng} / \mathrm{cell}$ ), causing a loss of $>70 \%$ of the cells within 4 days. Therefore based on this finding, amount below $40 \mu \mathrm{g} / \mathrm{mL}$ (or $1 \mathrm{ng} /$ cell) of oxidized MWCNTs could be used in CNT-mediated drug delivery for nanomedicine.

3.2. Determination of Characterization Methods. There are a number of useful techniques which could be employed to characterize the physicochemical structure and morphological properties of the drug-loaded $f$-CNTs. The detail usage of these characterizations in drug delivery will be discussed in the subsequent sections below. In order to obtain an accurate characterization of $f$-CNTs, all these techniques described here cannot be used on their own but must be used in complementary ways.

3.2.1. Vibrational Spectroscopies: FTIR, Near-IR, and Raman. Infrared (IR) spectroscopy is commonly used to gather information about the structure of unknown compounds or impurities remaining from chemical synthesis or molecules functionalized on the surface of the nanotubes. In the case of CNT-mediated drug delivery system, Fourier transform infrared spectroscopy (FTIR) is an appropriate technique to identify and confirm the chemical interaction between the CNTs and drugs through detailed investigation [80]. Moreover, it exhibits all the modification of the nanotubes structure and reveals the nature of constituents added to the nanotubes by studying the characteristic absorption bands. For example, Huang et al. characterized the synthesized product, doxorubicin-loaded SWCNT-chitosan-folate nanocarrier chemically modified by carboxylic group [45]. By extensively studying the FTIR spectra, the authors were able to confirm the presence of $-\mathrm{COOH}$ group on the oxidized CNTs, and the characterization of drug-loaded SWCNTs conjugate (Figure 2). Figure 2(a) is the FTIR spectra of pristine SWCNT and the absorption peak at $1540 \mathrm{~cm}^{-1}$ corresponding to the residue on the surface. The characteristic absorption peaks are observed at $1643 \mathrm{~cm}^{-1}$ and $3609 \mathrm{~cm}^{-1}$ in Figure 2(b), confirming the presence of carboxylic acid functionalized to the SWCNT. The multiple peaks derived from Figure 2(c) are assigned to the different ketone and quinone carbonyls of the pure DOX. Figure 2(d) confirmed the incorporation of DOX to SWCNT with absorption bands observed at $817 \mathrm{~cm}^{-1}$ and $1115 \mathrm{~cm}^{-1}$ (assigned to the vibration bands of $\mathrm{C}-\mathrm{O}-$ $\mathrm{CH}_{3}$ from DOX) and at $762 \mathrm{~cm}^{-1}$ and $874 \mathrm{~cm}^{-1}$ (assigned to the $\mathrm{N}-\mathrm{H}$ deformation bonds and primary amine $\mathrm{NH}_{2}$ from DOX). The characteristic absorption bands for DOX-loaded SWCNT encapsulated with chitosan-folic acid conjugate are observed in Figure 2(e), confirming the successful conjugation of DOX-loaded SWCNT encapsulated with chitosanfolic acid conjugate. Several groups also used the assigned characteristic FTIR absorption bands for the characterization of $f$-CNTs conjugated with various drugs and biomolecules $[34,46,54,55,58,63,81]$.

On the other hand, spectrofluorometer coupled with fluorescence microscope modified for near-IR (NIR) imaging can be used to investigate the cellular internalization of 

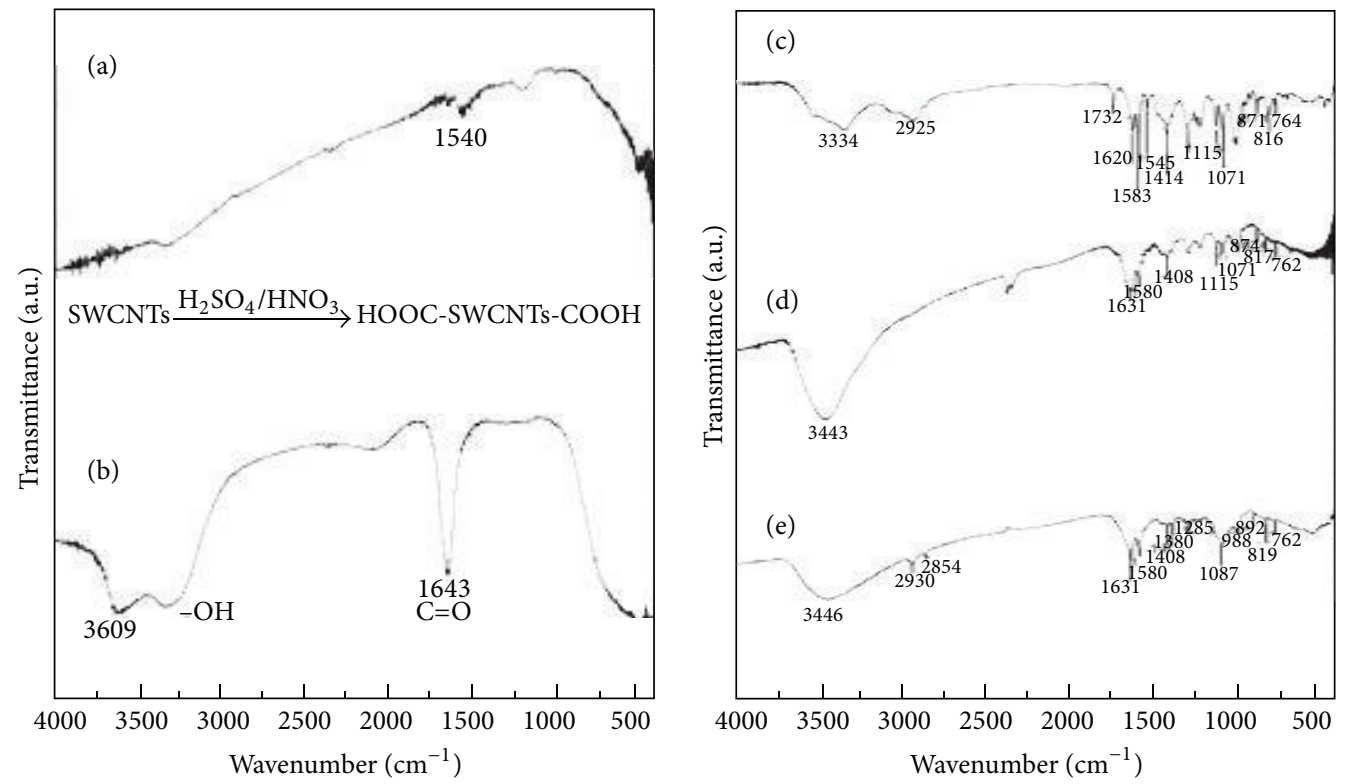

FIGURE 2: Fourier transform infrared (FTIR) spectra of (a) as-received SWCNT; (b) SWCNT functionalized with carboxylic acid; (c) DOX; (d) DOX-loaded SWCNT, and (e) DOX-loaded SWCNT encapsulated with chitosan-folic acid conjugate, respectively. Reproduced with permission from [45].

biocompatible $f$-CNTs in biological media [6]. The optical features of CNTs can be used to detect the conjugated biomolecules because they emitted fluorescence which could be observed in the NIR spectral region which covers from 900 to $1600 \mathrm{~nm}$ [82]. In addition, the CNT photoluminescence can be detected down to atomic level and it appears to be more photostable than quantum dots and organic dyes. Natural biomolecules and human tissues are relatively transparent and nonemissive in NIR light and, thus, this allows the light to penetrate deep into several centimeters thick in biological tissue. Furthermore, background cellular fluorescence is low in the NIR range, while most traditional fluorophores have almost the same emission signal as the tissue and biological media in the visible range $(800-1400 \mathrm{~nm})$. In addition, the band gap fluorescence emission is especially sensitive to surface defects on the $f$-CNTs, producing strong visible fluorescence signals upon the chemical functional groups, and the fluorescence energy is excitation wavelengths-dependent [83]. Therefore, the band gap fluorescence of $f$-CNTs is widely employed as a NIR imaging tool for biological systems.

Raman scattering measurement is another important nondestructive technique used to evaluate the quality (e.g., purity and defect density) of SWCNTs and to assess their functionalization. It has been widely used for the characterization of CNTs to obtain useful information about the changes in band width, intensities, and frequency of the radial breathing mode (RBM), disordered mode (D-band), and tangential mode (G-band) [66]. The presence of the functional groups conjugated to the side walls of SWCNTs will result in a shift in the intensity of the RBM and G- and D-band [67]. Typically, a shift in peak is indicating an interaction between the SWCNTs and the dispersing agents or functional moieties. Since the CNTs have the added advantage of having an inherent Raman effect, Raman spectroscopy has been used to evaluate the purity of SWCNTs by comparing the G-band intensity and the G/D ratio of the samples [66], to distinguish between carbon-based nanotubes [51], to characterize the structure of SWCNTs before and after functionalization [84], and to study the extent of covalently functionalized SWCNTs in comparison to the noncovalently functionalized SWCNTs [85]. Generally, the characteristic Raman features of CNTs can be summarized in Table 2 .

3.2.2. Thermal Gravimetry. Thermogravimetric analysis (TGA) is used to quantitatively determine the maximum temperature limit of use for a sample as well as a measurement for the determination of various functional groups attached to the surface of CNTs [86]. For example, carboxylic functional groups present at the defect site of CNTs are expected to decompose in temperature between 200 and $600^{\circ} \mathrm{C}$ as water and $\mathrm{CO}_{2}$ [87]. It has been known that CNTs can be heated up to $700^{\circ} \mathrm{C}$ under nitrogen atmosphere and that any changes in weight loss can be used to estimate the extent of CNTs functionalization [88]. Besides, Yudianti et al. [89] observed that side wall acid functionalization can cause a reduction in thermal stability (from $613.5^{\circ} \mathrm{C}$ in purified MWCNTs to $570^{\circ} \mathrm{C}$ in $f$-MWCNTs) mainly due to the breakdown of carbon double bond. Moreover, the metal impurities in the CNTs can also have a great impact on the thermal stability due to the catalyzation process of carbon oxidation [90]. Therefore, it is impossible to differentiate CNTs from metallic impurities because it is a nonselective method and, thus, it is used in complementary with other techniques. Alternatively, thermal analysis data can be presented as a maximum in the derivative weight curve known as derivative TGA (DTG) curve or onset temperature [89]. 
TABLE 2: The characteristic features of single-walled carbon nanotubes characterized by Raman spectroscopy. Adapted from [66, 67].

\begin{tabular}{|c|c|c|}
\hline $\begin{array}{l}\text { Characteristic } \\
\text { features }\end{array}$ & $\begin{array}{l}\text { Wavenumbers } \\
\qquad\left(\mathrm{cm}^{-1}\right)\end{array}$ & Comments \\
\hline $\begin{array}{l}\text { Radial } \\
\text { breathing } \\
\text { mode (RBM) }\end{array}$ & $100-300$ & $\begin{array}{l}\text { Radial movement of the nanotubes } \\
\left(\mathrm{A}_{\mathrm{lg}}\right) \text {. When resonating conditions } \\
\text { are met, only the Raman spectra of } \\
\text { single-walled carbon nanotubes } \\
\text { exhibit the RBM peak. }\end{array}$ \\
\hline $\begin{array}{l}\text { Disorder- } \\
\text { induced mode } \\
\text { (D-band) }\end{array}$ & $1300-1400$ & $\begin{array}{l}\text { Characteristic to nongraphitic } \\
\text { materials due to structural defects } \\
\text { in the } \mathrm{sp}^{3} \text { carbon atoms containing } \\
\text { carbonaceous impurities, which is } \\
\text { correlated with the extent of side } \\
\text { wall chemical functionalization. }\end{array}$ \\
\hline $\begin{array}{l}\text { Tangential } \\
\text { displacement } \\
\text { mode } \\
\text { (G-band) }\end{array}$ & $1500-1600$ & $\begin{array}{l}\text { Characteristic of carbon nanotubes, } \\
\text { corresponding to a splitting of the } \\
E_{2 g} \text { stretching mode of graphite, } \\
\text { could be superimposed with the } \\
\text { G-band of residual graphite. }\end{array}$ \\
\hline Second order & $2450-2650$ & $\begin{array}{l}\text { First overtone of the D band, often } \\
\text { called } G^{\prime} \text {-band. This second order } \\
\text { peak is sensitive to the charge } \\
\text { exchanged between CNTs and the } \\
\text { guest moiety. }\end{array}$ \\
\hline
\end{tabular}

3.2.3. Absorption Spectroscopy Using UV-Vis. The binding of drug or bioactive molecules to the $f$-CNTs can be detected using a UltraViolet-visible (UV-Vis) spectrophotometer [85, 91, 92]. For example, the real time drug release from the $f$ CNTs can be measured by comparing the absorbance value of the supernatant (after removal of $f$-CNTs in the solution) with the pure drug solution [92]. There is a significant difference in the drug binding and release efficiency based on different diameter of CNTs used in which smaller diameter nanotubes showed a faster release rate compared to larger diameter nanotubes [93]. This difference may be due to stronger $\pi$-stacking of biomolecules being absorbed onto larger surface of the tubes with flatter graphitic sidewalls. The drug release mechanism (diffusion mode) of the drug-loaded CNTs can also be altered by changing the surface functional groups of CNTs. This is because the interaction forces of the $f$-CNTs and drugs are based on hydrogen bonds and the strength of the bonds between $-\mathrm{OH}$ and $-\mathrm{COOH}$ groups is generally $\mathrm{pH}$-dependent [92].

3.2.4. NMR. Nuclear magnetic resonance (NMR) spectroscopy has been employed to investigate the synthesis and attachment of functional groups to CNTs and the most commonly used are solid state ${ }^{13} \mathrm{C}$ NMR. Solution state ${ }^{1} \mathrm{H}$ NMR is limited for the characterization of SWCNTs due to slow tumbling and low solubility of the SWCNTs results in broad spectra [94]. In addition to this, information like covalent functionalization cannot be obtained from ${ }^{1} \mathrm{H}$ NMR. Therefore, ${ }^{13} \mathrm{C}$ NMR has been used to characterize $f$-CNTs by studying the characteristic peaks in the magnetic environment. Several groups have conducted in-depth studies on the characterization of pristine CNTs and $f$-CNTs using solid state ${ }^{13} \mathrm{C}$ NMR spectroscopy. They have reported the ${ }^{13} \mathrm{C}$ spin-lattice relaxation behaviour of $f$-SWCNTs [95] and SWCNTs [96] as well as $f$-MWCNTs [97] and MWCNTs [98]. The $f$-CNTs are characterized by broad bands for protons which are in close proximity to the CNTs and the bands becoming sharper with distance. Recently, the use of two-dimensional (2D) NMR techniques has gained much attention since they can map out threedimensional (3D) interactions between or within molecules more efficiently [99]. This noninvasive technology has been popularly known as "NMR chromatography" due to its ability to isolate the compounds in a complicated mixture [100]. There have been numerous studies reported on the characterization of various bioconjugates using 2D NMR spectroscopy $[100,101]$.

3.2.5. Imaging Microscopies: SEM, TEM, STEM, AFM, and STM. Scanning electron microscopy (SEM) is a type of electron microscope and it is primarily used for the evaluation of morphology and suggesting the nature of material quality. SEM can be considered as the most generally used technique when it comes to the evaluation of $f$-CNTs [30, 34, 63]. Cheng et al. [47] had used SEM to confirm the purity of their synthesized nanotubes after acid purification by capturing a clear and without obvious amorphous carbon contamination image. The SEM images are a good source of information where details like CNTs diameters as well as the development of drug modified $f$-CNTs [63] can be obtained. When coupled with an energy dispersive X-ray analysis detector (SEM-EDX), catalyst impurity or different chemical elements in the CNTs structure can be detected [65]. Nonetheless, SEM is probably the only technique that can provide information on both morphology and the impurity content of CNTs.

Transmission electron microscopy (TEM) is a valuable tool used to characterize the microstructure of samples with very high spatial resolution. TEM provides qualitative information on the morphology (size and shape), structures and defects [102], impurities or contamination and functionalized molecules in a CNT sample $[53,55,81,103]$. Unlike SEM, it is unable to identify the presence of metallic content in CNTs. TEM has been widely used to image cellular uptake of drugloaded $f$-CNT and to monitor the CNT conjugates in the cell after cellular uptake [51]. Higher resolution images from TEM are used mostly to monitor the surface defects of individual nanotube wall and to distinguish between SWCNTs and MWCNTs [104].

Z-contrast scanning transmission electron microscopy (STEM) is one of the powerful tools for imaging individual heavy atoms in materials science applications and, most recently, this technique is used for imaging the distribution of platinum-based drug molecules attached to SWCNTs [105, 106]. STEM operates similarly as the normal SEM, by using a focused beam of electrons that scanned across a thin sample while some desired signal is then collected by a detector to form image at the atomic level [107]. It is an ideal technique for quantifying image intensities and determining the 
number of heavy metal-based drugs attached to nanotubes or other low-Z nanocarriers $[105,106]$.

Atomic force microscopy (AFM) is another option used to study the surface morphology and particle size parameters of CNTs [108]. Typically, AFM images provide useful information like the length and diameter distribution of the $f$-CNTs [52] as well as monitoring interactions between biological species such as blood proteins and CNTs [109]. The investigation between proteins and CNTs is important especially in biomedical applications because our blood circulation system will most likely be the first exposure to these nanoparticles. As such, Ge and coworkers [109] employed AFM in order to study proteins binding to the surface of SWCNTs. Based on the AFM images, they concluded that different proteins have different binding capabilities on SWCNTs surface. This selectivity of proteins can potentially affect the cellular responses (uptake, clearance, distribution, and delivery to the targeted sites) and, hence, result in different cytotoxicity.

The advantage of using scanning tunnelling microscopy (STM) to characterize carbon nanotubes is the generation of a 3D map of the nanotubes surface morphology which is consistent with the images derived from SEM [110]. In fact, the tunnelling electron effect enables simultaneously both the analysis of the CNTs at the atomic level as well as the electronic density of state. In order to use this technique, CNTs must be deposited on flat substrates coated with a thin layer of noble metal (mainly sapphire or quartz) [111] or highly oriented pyrolytic graphite (HOPG) [112]. This is to enable the electrons to flow to/from a STM tip. The STM images of CNTs can be very much depending on the curvature radius of the tip, CNTs diameter, and the different chiralities exhibited by the CNTs itself [113]. Consequently, the attachment of functional groups to the surface of CNTs and the mechanical stability of the bonding can also be analyzed using STM [112].

3.2.6. XPS. In the case of $f$-CNTs, X-ray photoelectron spectroscopy (XPS) can be used to analyze the surface chemical composition of the nanotubes. XPS is widely adopted for the studies of structure modification of the nanotubes side walls which is due to the chemical interaction with functionalized nanoparticles $[114,115]$. Zhang et al. have studied the bonding between MWCNTs and functional groups by XPS [81]. They confirmed the presence of oxygen atom peak with a binding energy $532.5 \mathrm{eV}$ on the surface of both MWCNTs-COOH and MWCNTs-PEG whereas pristine MWCNTs only recorded the presence of carbon. XPS analysis was also performed by Ciobotaru et al. on the covalent functionalization of DOX drug on the surface of SWCNTs through bonds formed between carboxyl moieties (SWCNTs) and amino groups (DOX) [116]. The chemical composition on the surface of purified SWCNTs, oxidized SWCNTs, and DOX $f$-SWCNTs nanocomposite has been investigated. For both purified and oxidized SWCNTs, the intensity peak of O1s increases after oxidation. From XPS spectrum of DOX functionalized SWCNTs, it can be observed that the intensity peak of N1s presented in DOX structure. The deconvolution of C1s peak of the DOX $f$-SWCNTs nanocomposite presents different shape due to the surface modification by transforming $\mathrm{O}-$ $\mathrm{C}=\mathrm{O}$ bonds into $\mathrm{N}-\mathrm{C}=\mathrm{O}$ bonds. By studying the composition of the elements on the surface of both PAMAM-MWCNTs nanocarrier and drug loaded PAMAM-MWCNTs, Zheng et al. observed a clear chemical shift in the N1s peak of the drug loaded PAMAM-MWCNTs towards the lower binding energy region (from 399.91 to 396.42) [63]. The shift was due to the functionalization of the MWCNTs indicating a successful attachment of the PAMAM-MWCNTs with the drug itself.

3.2.7. XRD. This nondestructive X-ray diffraction (XRD) method is generally used to obtain information on the interlayer spacing $\left(\mathrm{d}_{\mathrm{hkl}}\right)$, phase purity, and the structural strain of a compound. In the case of CNTs, multiple layers for MWCNTs, chiralities distribution, and diameters are also observed in the XRD pattern. There are two main characteristics that can be studied in the XRD pattern of most CNTs: (i) presence of a graphite-like peak $\left(\begin{array}{llll}0 & 0 & 2 & l\end{array}\right)$ and its interlayer spacing can be measured using Bragg's and (ii) a family of $(h k$ 0 ) peaks caused by the honeycomb lattice of single graphene sheet. Due to their unique intrinsic property, many studies have been conducted on the characterization of different $f$ CNTs using this method. For example, Jain et al. synthesized a novel cascade of $f$-MWCNTs which involved sequential steps of chemical modification via purification, carboxylation, acylation, amine modification, and galactose conjugation [117]. By studying the XRD spectra, the authors reported that the different functionalization process of MWCNTs did not change the cylindrical wall structure and remain similar to that of raw-purified MWCNTs.

In another study conducted by $\mathrm{Mi}$ et al. on the synthesis of polypyrrole/CNT (PPy/CNT) composites using methyl orange-iron (III) chloride-functionalized CNTs (CNT/MO$\mathrm{FeCl}_{3}$ ), they were able to prove that the organometallicfunctionalized CNTs were successfully developed via a novel microwave hydrothermal route by using XRD and other characterization methods [118]. The XRD patterns show several Bragg diffraction peaks $\left(11.8^{\circ}, 17.6^{\circ}, 20^{\circ}, 26.4^{\circ}, 28.6^{\circ}, 35.2^{\circ}\right.$, $39.3^{\circ}, 46.5^{\circ}$, and $55.9^{\circ}$ ) which are related to the crystalline structure of $\mathrm{CNT} / \mathrm{MO}-\mathrm{FeCl}_{3}$ composite. In comparison with $\mathrm{CNT} / \mathrm{MO}-\mathrm{FeCl}_{3}$ composite, a low intense broad peak was observed at $12.3-25.2^{\circ}$ for PPy/CNT composite, suggesting that the organometallic-functionalized CNTs had an amorphous structure. The XRD result demonstrated that, after the polymerization of pyrrole, the $\mathrm{MO}-\mathrm{FeCl}_{3}$ complex was removed from the CNTs and replaced with $\mathrm{PPy}$, resulting in the final product of PPy/CNT composite. Other types of functional moieties such as folate (serves as targeting moiety) and iron (acts as magnetic probe), which are commonly used in the application of CNT-based drug delivery system, can also be examined using XRD method [53].

3.2.8. Surface Area Analysis. The adsorption property (physisorption and chemisorption), specific surface area $\left(\mathrm{S}_{\mathrm{BET}}\right)$ and porosity (type of pore, pore size, pore volume, and pore distribution) of $f$-CNTs can be obtained using 
nitrogen [119], argon, and water adsorption-desorption measurements at different temperatures. This technique is widely used in various fields of study such as water treatment for heavy metal ions removal $[119,120]$, gas separation and recovery [121], hydrogen storage [122], and adsorption for anionic and cationic dyes [123]. In order to interpret the adsorption isotherms, Brunauer-Emmett-Teller (BET) method is used to calculate the surface areas [124] while $t$-plot [125] is used to determine the total pore volume and pore diameters. In a recent work carried out by Marques et al. on the study of oxygen functionalities generated on the surface of SWCNTs, the surface area $\left(\mathrm{S}_{\mathrm{BET}}\right)$ of the pristine and acid nitric treated SWCNTs was determined using $\mathrm{N}_{2}$ adsorption-desorption isotherms performed at $77 \mathrm{~K}$ [126]. They observed that the adsorption capacity of SWCNTs decreased with the increase of surface functional groups and structural defects present on the nanotubes. In another study conducted by Chigumbu et al. on the effects of using strong acids at different oxidation temperature for the preparation of drug loaded MWCNTs, they observed that the surface area increased as the temperature increased [127]. The authors attributed this to the fact that as the temperature of oxidation increased length and agglomeration (number of tubes in a bundle) of CNTs will reduce and, hence, the surface area is known to increase.

\section{Review on Bioassays Using Functionalized Carbon Nanotubes}

Over the past few years, $f$-CNTs have been extensively investigated and pursued as a potential nanocarrier for delivering various proteins, drugs, phytocompounds, peptides, nucleic acids, and bioactive molecules into living cells [6]. A summary of the $f$-CNTs in the applications of biomedical science has been reviewed in Figure 3. CNTs are particularly promising delivery system because they are nonimmunogenic [128], possess an extremely high drug loading capacity $[53,63]$, and are able to penetrate into cells without the use of neither external targeting moiety nor physical means of transporter system [22]. There has been significant recent progress reported in the literature on using $f$-CNTs as effective in vitro drug carriers. The following section will discuss the toxicological profile and biodistribution of the nanocarriers conjugated with different types of drugs via chemical functionalization.

\subsection{In Vitro Biocompatibility Assays}

4.1.1. Azithromycin (AZ). This antibiotic drug has been derived from erythromycin A with improved biological and pharmacodynamics properties over the parent compound. Darabi et al. used two different synthetic approaches (i.e., the acylation and thioamidation process on the nitrile groups) to functionalize SWCNTs with AZ via ester or thioamide bonds [34]. These cleavable bonds are able to control the release of drug from CNTs surfaces. According to the in vitro antibacterial assay against micrococcus luteus, AZ- $f$-SWCNTs showed a significant activity at $18 \mathrm{~h}$ of treatment.
4.1.2. Doxorubicin (DOX). DOX is a commonly used DNAinteracting drug for treatment of various cancers including ovarian, prostate, breast, brain, cervix, and lung cancers. The clinical application of this anthracycline antibiotic drug is limited due to its short half-life and severe toxicity to normal tissues, particularly the cardiovascular and gastrointestinal system. Therefore, many studies have been carried out in recent years to further enhance the therapeutic efficacy while reducing the toxic effects of the drug.

Li et al. employed a difunctionalization approach to covalently link both folic acid (FA) and iron (Fe) nanoparticles to the oxidized MWCNTs [53]. The resulting dual-targeted drug nanocarrier (DOX/FA-MWCNTS@Fe) possessing both magnetic (iron) and biological (folic acid) targeting capabilities was then further coated with DOX. DOX can be loaded onto the surface of the $f$-MWCNTs by nonspecific adsorption due to the strong $\pi-\pi$ stacking interaction of CNTs. The release of DOX from the system (DOX/FAMWCNTS@Fe) was a prolonged procedure and controlled by near infrared radiation. According to the in vitro experiments, the authors observed that the system exhibited the highest cytotoxicity among the five compounds (free DOX, DOX/MWCNTs, DOX/FA-MWCNTs, DOX/MWCNTs@Fe, and DOX/FA-MWCNTS@Fe) in the presence of the magnetic field. This can be attributed to the conjugation of both the magnetic iron nanoparticles and the FA functionality onto oxidized MWCNTs in which the system was able to target cancer cells through FA (active targeted manner) and stay at the sites of cancer cells via iron nanoparticles (passive targeted manner).

A targeted dual delivery system to brain glioma based on PEGylated oxidized MWCNTs (O-MWCNTs) modified with angiopep-2 (ANG) as targeting ligand was successfully prepared by Ren et al. [54]. Angiopep-2 is the ligand of low-density lipoprotein receptor-related protein (LRP) present on the blood-brain barrier and glioma cells. The biological safety of O-MWCNTs-PEG and O-MWCNTsPEG-ANG nanocarriers was evaluated by BCEC and C6 cytotoxicity using MTT assay. The results demonstrated that both complexes without DOX showed good biocompatibility and low toxicity with cells viabilities remaining at above $90 \%$. After C6 cells were incubated with DOX, DOX-O-MWCNTsPEG, and DOX-O-MWCNTs-PEG-ANG, the cells viabilities were reduced with the increase of DOX dosage with DOXO-MWCNTs-PEG-ANG exhibiting the highest cytotoxicity. The biodistribution of the compounds (FITC-O-MWCNTsPEG-ANG and FITC-O-MWCNTs-PEG) in BCEC and C6 cells demonstrated that FITC-O-MWCNTs-PEG-ANG was mostly localized in lysosomes and the cellular uptakes were significantly higher compared to that of FITC-O-MWCNTsPEG. This is mainly due to the interaction of angiopep and LRP receptor.

To explore the cancer targeting potential of the MWCNTs, Mehra et al. had developed a nanoformulation containing DOX and MWCNTs functionalized with D- $\alpha$-tocopheryl polyethylene glycol 1000 succinate (vitamin E TPGS) [55]. TPGS is a type of surfactant used to enhance the aqueous solubility and at the same time to prevent receptor-mediated endocytosis (RME) and multidrug resistance (MDR) when 


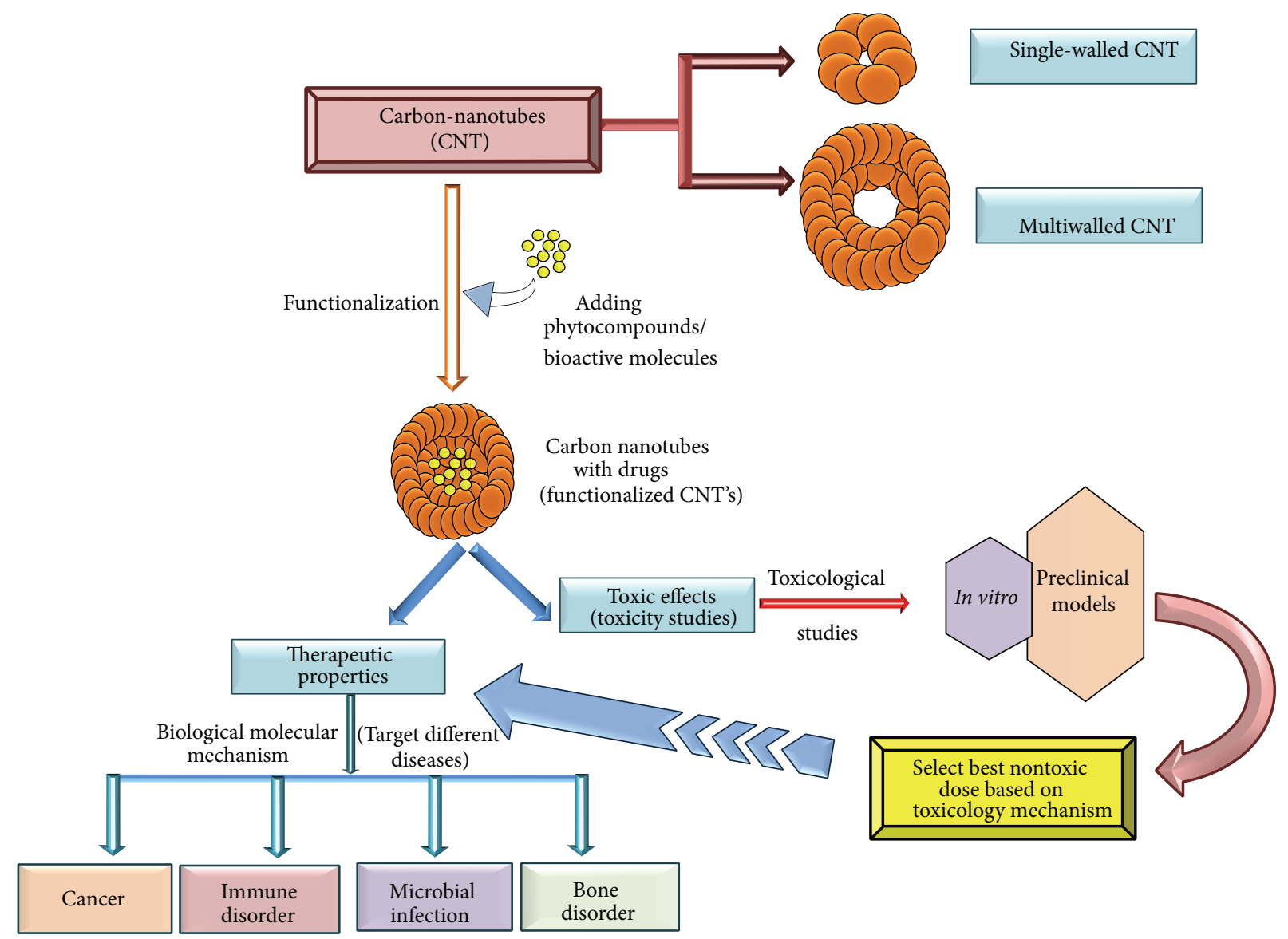

FIgURE 3: Applications of $f$-CNTs in nanomedicine.

coupled with carbon based nanomaterials. To evaluate the cancer targeting capability of the developed nanoformulation, MTT cytotoxicity assay was performed on MCF-7 cell line (human breast cancer derived from pleural perfusion). The developed MWCNTs nanoformulation was found to inhibit the growth of cancerous cells and this was due to apoptosis by intercalating DOX with DNA. The biodistribution studies showed that the DOX/TPGS-MWCNTs system was mostly taken up by the cancerous cells through receptor-mediated endocytosis as well as nanoneedle specific mechanism.

Another group of researchers, Karchemski et al., presented a new platform for drug delivery that is based on DOX-loaded liposomes covalently attached to MWCNTs [56]. The advantage of this novel approach is the high amount of drugs that can be transported by the CNTs via covalently attached liposomes and the ability to be administered effectively into cells. Thus, potential adverse systemic effects of CNTs when administered at high doses can be prevented. The in vitro cell viability test was carried out on HEK 293 cells treated with plain liposomes (control), $f$-MWCNTs, and drug-loaded liposomes attached to MWCNTs (CLC, CNT-liposomes conjugate). The toxicity of $f$-MWCNTs and liposomes was found to be dosedependent and the results showed that the CLC system demonstrated a $\sim 60 \%$ cell viability measured at concentration $50 \mu \mathrm{g} / \mathrm{mL}$. The cell uptake of $f$-MWCNTs, liposomes, and the CLC system was fluorescently monitored by using 3 labeling methods: labelling the $f$-MWCNTs by covalently linking N-(7-nitrobenz-2-oxa-1,3-diazol-4-yl)-1,2dihexadecanoyl-sn-glycero-3-phosphoethanolamine (NBD$\mathrm{PE}$ ) via amide bond, labelling the liposome's membrane by NBD-PE, and labelling the liposome's lumen by calcein. The uptake of the CLC system into HEK 293 cells was observed as a strong fluorescent signal indicating high calcein which is due to the release from liposome. The result has been further confirmed by in vitro experiments in human fibroblast cells in which liposomes alone were not taken up by cells but $f$ MWCNTs alone showed good uptake in the cell lines.

In view of the advantage of MWCNTs and iron oxide magnetic nanoparticles, Lu et al. synthesized a dual targeted delivery system using folate-attached magnetic MWCNTs for the delivery of DOX [59]. They used poly(acrylic acid) to functionalize MWCNTs via free radical polymerization and later conjugated with magnetic nanoparticles and targeting ligand FA. By conjugating magnetic nanoparticles to CNTs, it will, hence, provide an active targeting mechanism for drug delivery to tumor cells under the application of an external magnetic field. If endowed with FA molecules, CNTs can also enter cells via passive targeting mechanism. To compare the 
in vitro cytotoxicity and cellular uptake of the synthesized delivery system (DOX-FA-MN-MWCNTs) with free DOX, human glioblastoma cells (U87) were used in the cell culture experiments. The in vitro cytotoxicity studies showed that the cells viability of U87 cancer cells had reduced significantly by incubation with DOX-FA-MN-MWCNTs compared to free DOX. By comparing the cellular uptakes of both free DOX and DOX-FA-MN-MWCNTs, it was observed that the free DOX was confined within the nucleus of shrunken cells where DOX is chelated with DNA, whereas the delivery system was seen to localize in the cytoplasm of shrunken cells. Based on these studies, the authors claimed that the drug loaded delivery system could be transported across cell membrane through endocytosis mechanism and accumulated in the cytoplasm after internalization.

Heister et al. studied the oxidized SWCNTs with DOX via PEG functionalization [91]. DOX is known for its inherent fluorescence which facilitates cellular imaging in cells. They demonstrated that the CNT-mediated drug delivery system is $\mathrm{pH}$-dependent with a higher drug release of $44 \%$ at $\mathrm{pH}$ 5.5 and a drug release of only $7 \%$ at $\mathrm{pH} 7.4$ after $72 \mathrm{~h}$. Intracellular distribution of the system was studied using HeLa cells in which the cells were treated for $4 \mathrm{~h}$ and subsequently, the drug uptake was monitored by confocal microscopy. The results indicated that DOX was released from the CNTs into the cytoplasm and localized within the endosomes via endocytotic and energy-dependent uptake mechanism. When targeting agent folic acid was attached to the PEG chains of the drug-bound system, the selectivity and therapeutic efficacy of the system were greatly enhanced. This could be due to enhanced endocytotic uptake via RME mechanism.

4.1.3. Paclitaxel (PTX). PTX is an antimitotic agent used for the treatment of various solid tumours such as metastatic breast cancer, nonsmall cell lung cancer, and drug-resistant ovarian cancer. The clinical administration of PTX is greatly limited by inefficient distribution, lack of selectivity and poor aqueous solubility.

To improve its application in clinical therapy, Tian et al. designed an efficient targeting delivery system comprising MWCNTs, FA (targeting ligand), and QDs (fluorescence labeling probes) [49]. FA and QDs were covalently conjugated to the surface of PEI-modified MWCNTs using 1(3-(dimethylamino)propyl)-3-ethylcarbodiimide hydrochloride crosslinker while PTX was further loaded onto CNTs by noncovalent $\pi-\pi$ stacking interaction. In vitro cytotoxicity studies of $f$-MWCNTs-PTX-FA using MTT assay were conducted on HeLa cells for $48 \mathrm{~h}$. According to the results, the studied complex showed a significant enhancement in the cytotoxic capability compared to that of the PTX-MWCNTs-PEI and PTX alone. Confocal fluorescence microscopy was used to examine the cellular targeting ability of the supramolecular complex on HeLa cells and HUVEC cells. HeLa cells are known to have a high level of folate receptor overexpression whereas HUVEC cells exhibited low expressing levels of folate receptor. The authors observed that the HeLa cells treated with MWCNTs-PEI-FA-QDs had much brighter QDs fluorescence signals compared to those observed in HUVEC cells incubated with the same amount of MWCNTs-PEI-FA-QDs. These results indicated that the prepared MWCNTs-PEI-FA conjugates showed active targeting delivery efficiency.

Berlin and coworkers formulated PEG-hydrophilic carbon clusters (HCCs) system based on the noncovalent sequestration of the unmodified drug, paclitaxel (PTX, anticancer drug) [51]. These PEG-HCCs are a derivative from oxidized SWCNTs and were prepared by coupling PEG molecules to the carboxylic acids on the HCCs. In order to evaluate the in vitro efficacy, MTT assay was performed on cancer cell lines (head and neck cancer cells as well as breast cancer cells) treated with PTX/PEG-HCCs, PEGHCCs, and free PTX. Based on the results, the PTX/PEGHCCs formulation proved to be an effective drug delivery vehicle compared to PEG-HCCs and is stable for at least 20 weeks.

PTX is a drug with bulky structure and, hence, it has poor absorption on CNTs when conjugated to CNTdispersing polymer for drug delivery. As such, Shao et al. had constructed a novel approach for targeted delivery of the drug using SWCNTs-lipid-drug methodology in which a long chain lipid molecule (nontoxic docosanol) is covalently linked to the drug molecule [129]. The lipid-drug can then be attached onto the surface of CNTs through binding of the lipid "tail" in the drug molecule to CNTs by hydrophobic interactions. For targeting capability, FA was also being loaded onto CNTs. By conjugating FA to SWCNTs-lipidPTX, cell penetration capacity of the system in breast cancer cells had increased and exhibited improved drug efficacy in vitro compared to that of the free drug Taxol and nontargeted system at $48 \mathrm{~h}$ of treatment.

4.1.4. Gemcitabine (GEM). GEM is a nucleoside analogue and a S-phase specific cytotoxic agent for chemotherapy treatments like nonsmall cell lung cancer, haematologic malignancies, pancreatic cancer, head and neck squamous cell cancer, and tumours of the breast, ovary, germ cell, cervix, bladder, and biliary tract.

To improve the efficiency for the treatment of cancer lymph node metastasis, Yang et al. developed magnetic functionalized MWCNTs as drug vehicle for delivering GEM into the regional lymph nodes under the guidance of magnetic field [60]. To investigate the effects of CNTs on cells viability, in vitro cytotoxicity of only MWCNTs and GEM-loaded MWCNTs was performed on human pancreatic cancer cell lines (SW1990 and BxPC-3) using MTT assay. After incubation of $48 \mathrm{~h}$, the results showed that MWCNTs exhibited minimal cytotoxicity on the cancerous cells at high concentration of $25 \mu \mathrm{g} / \mathrm{mL}$, indicating nontoxic nature of the CNTs on the cancerous cells. As for the GEM-loaded MWCNTs, cells viability of the compound showed a dosedependent decrease manner. The authors also observed that the MWCNTs were rapidly internalized by BxPC-3 cells and located in the perinuclear region.

4.1.5. Daunorubicin (DAU). DAU is a commonly used anthracycline antibiotics for the treatment of leukemia (acute 
myeloid leukemia and acute lymphocytic leukemia). However, its therapeutic efficacy is limited by cumulative myelosuppression and cardiotoxicity which leads to unwanted side effects.

In order to maximize the efficacy of DAU and at the same time minimize their negative effects, sgc8c aptamer (the use of this aptamer is to target leukemia biomarker protein tyrosine kinase-7) had been used to functionalize onto SWCNTs and the resulting water soluble aptamerSWCNTs complex was further loaded with DAU [64]. These aptamers are single-stranded DNA or RNA nanomaterials with sizes ranging from 20 to 80 nucleotides [130]. They could selectively bind to small molecules, proteins, and whole cells. Cytotoxic studies (MTT assay) were conducted on Molt-4 (target) cell line and B lymphocyte human myeloma (U266, nontarget) cell line and the cells were incubated with DAU-aptamer-SWCNTs and DAU alone for $4 \mathrm{~h}$. The cytotoxic analysis showed that the DAU-aptamer-SWCNTs were internalized to Molt- 4 cells, but not to U266 cells and the conjugate was also less cytotoxic in U266 cells in comparison with DAU component.

4.1.6. Cisplatin (CIS). CIS (cis-diamminedichloroplatinum (II)) is an anticancer drug widely used to treat different types of cancer such as testicular, gastrointestinal, bladder, and ovarian cancers. However, this drug has acute and cumulative renal toxicity [131]. Thus, new platinum-based drugs are still being produced in an attempt to surpass the side effects and inherent toxicities of CIS, but only a small number of these drugs have demonstrated potential interests in clinical trials. In order to mask the toxicity of platinumbased drug, one can employ drug carriers as delivery systems.

In view of this, a group of researchers used hydrothermally oxidized SWCNTs as delivery vehicle for the loading of platinum $(\mathrm{Pt})$-based drug prepared differently using water or dimethylformamide (DMF) as solvents [106]. They observed that the drug is rapidly delivered into the cells for system prepared using DMF as solvent, especially for the first $10 \mathrm{~h}$ of treatment. However, when it comes to the proliferation assays performed on human melanoma (CRL 1872) cancer cells in vitro, the effect of solvents was obviously significant. The studies showed that the sample prepared by water solution displayed enhanced cytotoxicity profile than the sample prepared by DMF, especially at the lowest concentration of the drug. Their results indicated that the drug delivery system prepared by water solution leads to better results for small concentrations in comparison with DMF.

Another group employed a different methodology by using SWCNTs functionalized with drug CIS and epidermal growth factor (EGF) to design an effective drug delivery system that specifically targets squamous cancer cells [132]. The researchers reported that the SWCNTsCIS-EGF demonstrates superior efficacy to SWCNTs-CIS by showing selectivity to the overexpress epidermal growth factor receptor (EGFR) on head and neck squamous cell carcinoma.

\section{Conclusions}

The developing potential of $f$-CNTs in nanomedicine has become an increasingly mature topic. As a result, many biocompatible $f$-CNT conjugates and related systems have been synthesized and developed for in-depth investigations on their potential biomedical applications. This is because chemically modified $f$-CNTs are not immunogenic and show remarkable carrier features with a strong tendency to cross cell membranes. While many of the in vitro biodistribution and cytotoxicity results of the CNTs targeting drug delivery system are promising, additional in vivo studies using a variety of animal models over a longer time frame are required and need to be carefully studied prior to clinical trials. Even though there are many contradictory reports associated with the toxicity of $f$-CNTs being utilized as a potential drug vehicle in drug design and delivery, findings described herein strongly suggest that the $f$-CNT bioconjugates hold great potential in the field of nanomedicine.

\section{Conflict of Interests}

The authors declare that there is no conflict of interests regarding the publication of this paper.

\section{Acknowledgments}

The authors are grateful to the Ministry of Science, Technology and Innovation of Malaysia (MOSTI), for funding this project under National Nanotechnology Directorate, Grant no. NND/NA/(1)/TD11-010 (UPM vot no. 5489100) and MyPhD scholarship under the MyBrain15 program for Julia M. Tan.

\section{References}

[1] T. Fu, R. Liu, J. Lv, and Z. Li, "Influence of acid treatment on $\mathrm{N}$-doped multi-walled carbon nanotube supports for FischerTropsch performance on cobalt catalyst," Fuel Processing Technology, vol. 122, pp. 49-57, 2014.

[2] D. Silambarasan, V. J. Surya, V. Vasu, and K. Iyakutti, "Investigation of single-walled carbon nanotubes-titanium metal composite as a possible hydrogen storage medium," International Journal of Hydrogen Energy, vol. 38, no. 34, pp. 14654-14660, 2013.

[3] G. Sanborn, S. Turano, and W. J. Ready, "Oxygen plasma resurrection of triode type carbon nanotube field emission cathodes," Diamond and Related Materials, vol. 43, pp. 1-4, 2014.

[4] Y. Liu, K. Shi, and I. Zhitomirsky, "New colloidal route for electrostatic assembly of oxide nanoparticle-carbon nanotube composites," Colloids and Surfaces A: Physicochemical and Engineering Aspects, vol. 446, pp. 15-22, 2014.

[5] A. Siriviriyanun, T. Imae, and N. Nagatani, "Electrochemical biosensors for biocontaminant detection consisting of carbon nanotubes, platinum nanoparticles, dendrimers, and enzymes," Analytical Biochemistry, vol. 443, no. 2, pp. 169-171, 2013.

[6] P. Lee, Y. Chiou, J. Wong, C. Peng, and M. Shieh, “Targeting colorectal cancer cells with single-walled carbon nanotubes conjugated to anticancer agent SN-38 and EGFR antibody," Biomaterials, vol. 34, no. 34, pp. 8756-8765, 2013. 
[7] S. M. N. Mohsin, M. Z. Hussein, S. H. Sarijo, S. Fakurazi, P. Arulselvan, and Y. H. Taufiq-Yap, "Characterisation and cytotoxicity assessment of UV absorbers-intercalated zinc/aluminiumlayered double hydroxides on dermal fibroblast cells," Science of Advanced Materials, vol. 6, no. 4, pp. 648-658, 2014.

[8] B. Saifullah, M. Z. Hussein, S. H. Hussein-Al-Ali, P. Arulselvan, and S. Fakurazi, "Antituberculosis nanodelivery system with controlled-release properties based on para-amino salicylatezinc aluminum-layered double-hydroxide nanocomposites," Drug Design, Development and Therapy, vol. 7, pp. 1365-1375, 2013.

[9] F. Barahuie, M. Z. Hussein, S. H. Hussein-Al-Ali, P. Arulselvan, S. Fakurazi, and Z. Zainal, "Preparation and controlled-release studies of a protocatechuic acid-magnesium/aluminumlayered double hydroxide nanocomposite," International Journal of Nanomedicine, vol. 8, pp. 1975-1987, 2013.

[10] A. U. Kura, S. H. H. A. Ali, M. Z. Hussein, S. Fakurazi, and P. Arulselvan, "Development of a controlled-release antiparkinsonian nanodelivery system using levodopa as the active agent," International Journal of Nanomedicine, vol. 8, pp. 11031110, 2013.

[11] S. M. N. Mohsin, M. Z. Hussein, S. H. Sarijo, S. Fakurazi, P. Arulselvan, and T. Y. Hin, "Synthesis of (cinnamate-zinc layered hydroxide) intercalation compound for sunscreen application," Chemistry Central Journal, vol. 7, no. 1, article 26, 2013.

[12] S. M. N. Mohsin, M. Z. Hussein, S. H. Sarijo, S. Fakurazi, P. Arulselvan, and Y. H. Taufiq-Yap, "Optimization of UV absorptivity of layered double hydroxide by intercalating organic UVabsorbent molecules," Journal of Biomedical Nanotechnology, vol. 10, no. 8, pp. 1490-1500, 2014.

[13] X. Cao, W. Deng, M. Fu et al., "Seventy-two-hour release formulation of the poorly soluble drug silybin based on porous silica nanoparticles: in vitro release kinetics and in vitro/in vivo correlations in beagle dogs," European Journal of Pharmaceutical Sciences, vol. 48, no. 1-2, pp. 64-71, 2013.

[14] R. Ghaffarian, T. Bhowmick, and S. Muro, "Transport of nanocarriers across gastrointestinal epithelial cells by a new transcellular route induced by targeting ICAM-1," Journal of Controlled Release, vol. 163, no. 1, pp. 25-33, 2012.

[15] L. Zhang, H. Xue, Z. Cao, A. Keefe, J. Wang, and S. Jiang, "Multifunctional and degradable zwitterionic nanogels for targeted delivery, enhanced MR imaging, reduction-sensitive drug release, and renal clearance," Biomaterials, vol. 32, no. 20, pp. 4604-4608, 2011.

[16] D. S. Bethune, C. H. Kiang, M. S. de Vries et al., "Cobaltcatalysed growth of carbon nanotubes with single-atomic-layer walls," Nature, vol. 363, no. 6430, pp. 605-607, 1993.

[17] S. Iijima and T. Ichihashi, "Single-shell carbon nanotubes of 1nm diameter," Nature, vol. 363, no. 6430, pp. 603-605, 1993.

[18] H. Dai, "Carbon nanotubes: opportunities and challenges," Surface Science, vol. 500, no. 1-3, pp. 218-241, 2002.

[19] T. G. Abi, T. Karmakar, and S. Taraphder, "Proton affinity of polar amino acid sidechain analogues anchored to the outer wall of single walled carbon nanotubes," Computational and Theoretical Chemistry, vol. 1010, pp. 53-66, 2013.

[20] W. Feng and P. Ji, "Enzymes immobilized on carbon nanotubes," Biotechnology Advances, vol. 29, no. 6, pp. 889-895, 2011.

[21] Q. Chen, T. Kaneko, and R. Hatakeyama, "Characterization of pulse-driven gas-liquid interfacial discharge plasmas and application to synthesis of gold nanoparticle-DNA encapsulated carbon nanotubes," Current Applied Physics, vol. 11, no. 5, pp. S63-S66, 2011.
[22] K. Kostarelos, L. Lacerda, G. Pastorin et al., "Cellular uptake of functionalized carbon nanotubes is independent of functional group and cell type," Nature Nanotechnology, vol. 2, no. 2, pp. 108-113, 2007.

[23] A. E. Porter, M. Gass, K. Muller, J. N. Skepper, P. A. Midgley, and M. Welland, "Direct imaging of single-walled carbon nanotubes in cells," Nature Nanotechnology, vol. 2, no. 11, pp. 713-717, 2007.

[24] S. Iijima, "Carbon nanotubes: past, present, and future," Physica B: Condensed Matter, vol. 323, no. 1-4, pp. 1-5, 2002.

[25] A. Hirsch, "Funktionalisierung von einwandigen Kohlenstoffnanoröhren," Angewandte Chemie, vol. 114, pp. 1933-1939, 2002.

[26] R. M. Reilly, "Carbon nanotubes: potential benefits and risks of nanotechnology in nuclear medicine," The Journal of Nuclear Medicine, vol. 48, no. 7, pp. 1039-1042, 2007.

[27] L. Huang, B. Wu, J. Chen et al., "Synthesis of single-walled carbon nanotubes by an arc-discharge method using selenium as a promoter," Carbon, vol. 49, no. 14, pp. 4792-4800, 2011.

[28] Y. Jung, J. Song, W. Huh, D. Cho, and Y. Jeong, "Controlling the crystalline quality of carbon nanotubes with processing parameters from chemical vapor deposition synthesis," Chemical Engineering Journal, vol. 228, pp. 1050-1056, 2013.

[29] R. Yuge, K. Toyama, T. Ichihashi, T. Ohkawa, Y. Aoki, and T. Manako, "Characterization and field emission properties of multi-walled carbon nanotubes with fine crystallinity prepared by $\mathrm{CO}_{2}$ laser ablation," Applied Surface Science, vol. 258, no. 18, pp. 6958-6962, 2012.

[30] C. Dong, A. S. Campell, R. Eldawud, G. Perhinschi, Y. Rojanasakul, and C. Z. Dinu, "Effects of acid treatment on structure, properties and biocompatibility of carbon nanotubes," Applied Surface Science, vol. 264, pp. 261-268, 2013.

[31] S. Peretz and O. Regev, "Carbon nanotubes as nanocarriers in medicine," Current Opinion in Colloid \& Interface Science, vol. 17, no. 6, pp. 360-368, 2012.

[32] H. Qi, C. Ling, R. Huang et al., "Functionalization of singlewalled carbon nanotubes with protein by click chemistry as sensing platform for sensitized electrochemical immunoassay," Electrochimica Acta, vol. 63, pp. 76-82, 2012.

[33] Y. Hao, P. Xu, C. He et al., "Impact of carbondiimide crosslinker used for magnetic carbon nanotube mediated GFP plasmid delivery," Nanotechnology, vol. 22, no. 28, Article ID 285103, pp. $1-9,2011$.

[34] H. R. Darabi, A. Roozkhosh, M. J. Tehrani et al., "Characterization of ester- or thioamide-functionalized single-walled carbon nanotube-azithromycin conjugates," Applied Surface Science, vol. 288, pp. 122-129, 2014.

[35] G. Ghini, C. Trono, A. Giannetti et al., "Carbon nanotubes modified with fluorescein derivatives for $\mathrm{pH}$ nanosensing," Sensors and Actuators B, vol. 179, pp. 163-169, 2013.

[36] K. A. S. Fernando, Y. Lin, W. Wang et al., "Diminished band-gap transitions of single-walled carbon nanotubes in complexation with aromatic molecules," Journal of the American Chemical Society, vol. 126, no. 33, pp. 10234-10235, 2004.

[37] E. Heister, V. Neves, C. Tîlmaciu et al., "Triple functionalisation of single-walled carbon nanotubes with doxorubicin, a monoclonal antibody, and a fluorescent marker for targeted cancer therapy," Carbon, vol. 47, no. 9, pp. 2152-2160, 2009.

[38] M. Sheikholeslam, M. Pritzker, and P. Chen, "Hybrid peptidecarbon nanotube dispersions and hydrogels," Carbon, vol. 71, pp. 284-293, 2014.

[39] P. R. Dalmasso, M. L. Pedano, and G. A. Rivas, "Dispersion of multi-wall carbon nanotubes in polyhistidine: characterization 
and analytical applications," Analytica Chimica Acta, vol. 710, pp. 58-64, 2012.

[40] P. Oleszczuk and B. Xing, "Influence of anionic, cationic and nonionic surfactants on adsorption and desorption of oxytetracycline by ultrasonically treated and non-treated multiwalled carbon nanotubes," Chemosphere, vol. 85, no. 8, pp. 1312-1317, 2011.

[41] Y. Yan, J. Cui, P. Pötschke, and B. Voit, "Dispersion of pristine single-walled carbon nanotubes using pyrene-capped polystyrene and its application for preparation of polystyrene matrix composites," Carbon, vol. 48, no. 9, pp. 2603-2612, 2010.

[42] J. Filip, J. Šefčovičová, P. Tomčík, P. Gemeiner, and J. Tkac, “A hyaluronic acid dispersed carbon nanotube electrode used for a mediatorless NADH sensing and biosensing," Talanta, vol. 84, no. 2, pp. 355-361, 2011.

[43] A. L. Alpatova, W. Shan, P. Babica et al., "Single-walled carbon nanotubes dispersed in aqueous media via non-covalent functionalization: effect of dispersant on the stability, cytotoxicity, and epigenetic toxicity of nanotube suspensions," Water Research, vol. 44, no. 2, pp. 505-520, 2010.

[44] S. W. Kim, T. Kim, Y. S. Kim et al., "Surface modifications for the effective dispersion of carbon nanotubes in solvents and polymers," Carbon, vol. 50, no. 1, pp. 3-33, 2012.

[45] H. Huang, Q. Yuan, J. S. Shah, and R. D. K. Misra, "A new family of folate-decorated and carbon nanotube-mediated drug delivery system: Synthesis and drug delivery response," Advanced Drug Delivery Reviews, vol. 63, no. 14-15, pp. 13321339, 2011.

[46] G. M. Neelgund, A. Oki, and Z. Luo, "Antimicrobial activity of CdS and Ag2S quantum dots immobilized on poly(amidoamine) grafted carbon nanotubes," Colloids and Surfaces B: Biointerfaces, vol. 100, pp. 215-221, 2012.

[47] J. Cheng, M. J. Meziani, Y. P. Sun, and S. H. Cheng, "Poly(ethylene glycol)-conjugated multi-walled carbon nanotubes as an efficient drug carrier for overcoming multidrug resistance," Toxicology and Applied Pharmacology, vol. 250, no. 2, pp. 184-193, 2011.

[48] S. Park, J. Shin, J. Lee, and M. Cha, "Manipulation of NIH3T3 cells with functionalized single-walled carbon nanotubes under a magnetic field," Materials Letters, vol. 68, pp. 378-381, 2012.

[49] Z. Tian, Y. Shi, M. Yin, H. Shen, and N. Jia, "Functionalized multiwalled carbon nanotubesanticancer drug carriers: synthesis, targeting ability and antitumor activity," Nano Biomedicine and Engineering, vol. 3, no. 3, pp. 157-162, 2011.

[50] Z. Ji, G. Lin, Q. Lu et al., “Targeted therapy of SMMC-7721 liver cancer in vitro and in vivo with carbon nanotubes based drug delivery system," Journal of Colloid and Interface Science, vol. 365, no. 1, pp. 143-149, 2012.

[51] J. M. Berlin, A. D. Leonard, T. T. Pham et al., "Effective drug delivery, in vitro and in vivo, by carbon-based nanovectors noncovalently loaded with unmodified paclitaxel," ACS Nano, vol. 4, no. 8, pp. 4621-4636, 2010.

[52] M. Adeli, F. Hakimpoor, M. Ashiri, R. Kabiri, and M. Bavadi, "Anticancer drug delivery systems based on noncovalent interactions between carbon nanotubes and linear-dendritic copolymers," Soft Matter, vol. 7, no. 8, pp. 4062-4070, 2011.

[53] R. Li, R. Wu, L. Zhao et al., "Folate and iron difunctionalized multiwall carbon nanotubes as dual-targeted drug nanocarrier to cancer cells," Carbon, vol. 49, no. 5, pp. 1797-1805, 2011.
[54] J. Ren, S. Shen, D. Wang et al., "The targeted delivery of anticancer drugs to brain glioma by PEGylated oxidized multiwalled carbon nanotubes modified with angiopep-2," Biomaterials, vol. 33, no. 11, pp. 3324-3333, 2012.

[55] N. K. Mehra, A. K. Verma, P. R. Mishra, and N. K. Jain, "The cancer targeting potential of D- $\alpha$-tocopheryl polyethylene glycol 1000 succinate tethered multi walled carbon nanotubes," Biomaterials, vol. 35, no. 15, pp. 4573-4588, 2014.

[56] F. Karchemski, D. Zucker, Y. Barenholz, and O. Regev, "Carbon nanotubes-liposomes conjugate as a platform for drug delivery into cells," Journal of Controlled Release, vol. 160, no. 2, pp. 339345, 2012.

[57] C. Li, K. Yang, Y. Zhang et al., "Highly biocompatible multiwalled carbon nanotube-chitosan nanoparticle hybrids as protein carriers," Acta Biomaterialia, vol. 7, no. 8, pp. 3070-3077, 2011.

[58] X. Ling, Y. Wei, L. Zou, and S. Xu, "Functionalization and dispersion of multiwalled carbon nanotubes modified with poly-L-lysine," Colloids and Surfaces A: Physicochemical and Engineering Aspects, vol. 443, pp. 19-26, 2014.

[59] Y.-J. Lu, K.-C. Wei, C.-C. M. Ma, S.-Y. Yang, and J.-P. Chen, "Dual targeted delivery of doxorubicin to cancer cells using folate-conjugated magnetic multi-walled carbon nanotubes," Colloids and Surfaces B: Biointerfaces, vol. 89, no. 1, pp. 1-9, 2012.

[60] F. Yang, C. Jin, D. Yang et al., "Magnetic functionalised carbon nanotubes as drug vehicles for cancer lymph node metastasis treatment," European Journal of Cancer, vol. 47, no. 12, pp. 18731882, 2011.

[61] A. Albini, V. Mussi, A. Parodi et al., "Interactions of singlewall carbon nanotubes with endothelial cells," Nanomedicine: Nanotechnology, Biology, and Medicine, vol. 6, no. 2, pp. 277288, 2010.

[62] R. Dvash, A. Khatchatouriants, L. J. Solmesky et al., "Structural profiling and biological performance of phospholipidhyaluronan functionalized single-walled carbon nanotubes," Journal of Controlled Release, vol. 170, no. 2, pp. 295-305, 2013.

[63] X. Zheng, T. Wang, H. Jiang et al., "Incorporation of Carvedilol into PAMAM-functionalized MWNTs as a sustained drug delivery system for enhanced dissolution and drug-loading capacity," Asian Journal of Pharmaceutical Sciences, vol. 8, pp. 278-286, 2013.

[64] S. M. Taghdisi, P. Lavaee, M. Ramezani, and K. Abnous, "Reversible targeting and controlled release delivery of daunorubicin to cancer cells by aptamer-wrapped carbon nanotubes," European Journal of Pharmaceutics and Biopharmaceutics, vol. 77, no. 2, pp. 200-206, 2011.

[65] J. J. Castillo, T. Rindzevicius, L. V. Novoa et al., "Non-covalent conjugates of single-walled carbon nanotubes and folic acid for interaction with cells over-expressing folate receptors," Journal of Materials Chemistry B, vol. 1, no. 10, pp. 1475-1481, 2013.

[66] Y. Miyata, K. Mizuno, and H. Kataura, "Purity and defect characterization of single-wall carbon nanotubes using Raman spectroscopy," Journal of Nanomaterials, vol. 2011, Article ID 786763, 7 pages, 2011.

[67] S. Hussain, P. Jha, A. Chouksey et al., "Spectroscopic investigation of modified single wall carbon nanotube (SWCNT)," Journal of Modern Physcis, vol. 2, no. 6, pp. 538-543, 2011.

[68] R. Podila and J. M. Brown, “Toxicity of engineered nanomaterials: a physicochemical perspective," Journal of Biochemical and Molecular Toxicology, vol. 27, no. 1, pp. 50-55, 2013. 
[69] A. Fraczek-Szczypta, E. Menaszek, and S. Blazewicz, "Some observations on carbon nanotubes susceptibility to cell phagocytosis," Journal of Nanomaterials, vol. 2011, Article ID 473516, 8 pages, 2011.

[70] X. Zhao and R. Liu, "Recent progress and perspectives on the toxicity of carbon nanotubes at organism, organ, cell, and biomacromolecule levels," Environment International, vol. 40, no. 1, pp. 244-255, 2012.

[71] S. K. Sohaebuddin, P. T. Thevenot, D. Baker, J. W. Eaton, and L. Tang, "Nanomaterial cytotoxicity is composition, size, and cell type dependent," Particle and Fibre Toxicology, vol. 7, article 22, 2010.

[72] P. Cherukuri, S. M. Bachilo, S. H. Litovsky, and R. B. Weisman, "Near-infrared fluorescence microscopy of single-walled carbon nanotubes in phagocytic cells," Journal of the American Chemical Society, vol. 126, no. 48, pp. 15638-15639, 2004.

[73] J. E. N. Dolatabadi, Y. Omidi, and D. Losic, "Carbon nanotubes as an advanced drug and gene delivery nanosystem," Current Nanoscience, vol. 7, no. 3, pp. 297-314, 2011.

[74] C. P. Firme III and P. R. Bandaru, "Toxicity issues in the application of carbon nanotubes to biological systems," Nanomedicine, vol. 6, no. 2, pp. 245-256, 2010.

[75] J.-P. Kaiser, M. Roesslein, T. Buerki-Thurnherr, and P. Wick, "Carbon nanotubes-curse or blessing," Current Medicinal Chemistry, vol. 18, no. 14, pp. 2115-2128, 2011.

[76] S. Koyama, Y. A. Kim, T. Hayashi et al., "In vivo immunological toxicity in mice of carbon nanotubes with impurities," Carbon, vol. 47, no. 5, pp. 1365-1372, 2009.

[77] L. Meng, A. Jiang, R. Chen et al., "Inhibitory effects of multiwall carbon nanotubes with high iron impurity on viability and neuronal differentiation in cultured PC12 cells," Toxicology, vol. 313, no. 1, pp. 49-58, 2012.

[78] A. Jos, S. Pichardo, M. Puerto, E. Sánchez, A. Grilo, and A. M. Cameán, "Cytotoxicity of carboxylic acid functionalized single wall carbon nanotubes on the human intestinal cell line Caco2," Toxicology in Vitro, vol. 23, no. 8, pp. 1491-1496, 2009.

[79] A. Patlolla, B. Knighten, and P. Tchounwou, "Multi-walled carbon nanotubes induce cytotoxicity, genotoxicity and apoptosis in normal human dermal fibroblast cells," Ethnicity \& Disease, vol. 20, no. 1, pp. S65-S72, 2010.

[80] I. Bhatnagar, J. Venkatesan, and S. K. Kim, "Polymer functionalized single walled carbon nanotubes mediated drug delivery of gliotoxin in cancer cells," Journal of Biomedical Nanotechnology, vol. 10, no. 1, pp. 120-130, 2014.

[81] T. Zhang, M. Tang, L. Kong et al., "Comparison of cytotoxic and inflammatory responses of pristine and functionalized multiwalled carbon nanotubes in RAW 264.7 mouse macrophages," Journal of Hazardous Materials, vol. 219-220, pp. 203-212, 2012.

[82] C. Ménard-Moyon, K. Kostarelos, M. Prato, and A. Bianco, "Functionalized carbon nanotubes for probing and modulating molecular functions," Chemistry \& Biology, vol. 17, no. 2, pp. 107-115, 2010.

[83] L. Minati, G. Speranza, I. Bernagozzi, S. Torrengo, A. Chiasera, and M. Ferrari, "Luminescent short thiol-functionalized multiwall carbon nanotubes," Diamond and Related Materials, vol. 20, no. 7, pp. 1046-1049, 2011.

[84] N. Hadidi, F. Kobarfard, N. Nafissi-Varcheh, and R. Aboofazeli, "Optimization of single-walled carbon nanotube solubility by noncovalent PEGylation using experimental design methods," International Journal of Nanomedicine, vol. 6, pp. 737-746, 2011.
[85] W. Chidawanyika and T. Nyokong, "Characterization of aminefunctionalized single-walled carbon nanotube-low symmetry phthalocyanine conjugates," Carbon, vol. 48, no. 10, pp. 2831$2838,2010$.

[86] F. A. Abuilaiwi, T. Laoui, M. Al-Harthi, and M. A. Atieh, "Modification and functionalization of multiwalled carbon nanotube (MWCNT) via fischer esterification," The Arabian Journal for Science and Engineering, vol. 35, no. 1, pp. 37-48, 2010.

[87] H. R. Aghabozorg, S. S. Kish, and A. M. Rashidi, "Solubility of functionalized carbon nanotubes in different solvents," Journal of Applied Chemical Researches, vol. 3, no. 12, pp. 29-33, 2010.

[88] S. Ilbasmis-Tamer, S. Yilmaz, E. Banoğlu, and I. T. Değim, "Carbon nanotubes to delivery drug molecules," Journal of Biomedical Nanotechnology, vol. 6, pp. 20-27, 2010.

[89] R. Yudianti, H. Onggo, Sudirman, Y. Saito, T. Iwata, and J. Azuma, "Analysis of functional group sited on multi-wall carbon nanotube surface," The Open Materials Science Journal, vol. 5, pp. 242-247, 2011.

[90] M. E. Itkis, D. E. Perea, R. Jung, S. Niyogi, and R. C. Haddon, "Comparison of analytical techniques for purity evaluation of single-walled carbon nanotubes," Journal of the American Chemical Society, vol. 127, no. 10, pp. 3439-3448, 2005.

[91] E. Heister, V. Neves, C. Lamprecht, S. R. P. Silva, H. M. Coley, and J. McFadden, "Drug loading, dispersion stability, and therapeutic efficacy in targeted drug delivery with carbon nanotubes," Carbon, vol. 50, no. 2, pp. 622-632, 2012.

[92] R. Zhang and H. Olin, "Carbon nanomaterials as drug carriers: real time drug release investigation," Materials Science and Engineering C, vol. 32, no. 5, pp. 1247-1252, 2012.

[93] Z. Liu, X. Sun, N. Nakayama-Ratchford, and H. Dai, "Supramolecular chemistry on water-soluble carbon nanotubes for drug loading and delivery," ACS Nano, vol. 1, no. 1, pp. 50-56, 2007.

[94] L. Zeng and A. R. Barron, Characterization of Covalently Functionalized Single-Walled Carbon Nanotubes, Connexions Web Site, 2010, http://cnx.org/content/m22299/1.4/.

[95] H. Peng, L. B. Alemany, J. L. Margrave, and V. N. Khabashesku, "Sidewall carboxylic acid functionalization of single-walled carbon nanotubes," Journal of the American Chemical Society, vol. 125, no. 49, pp. 15174-15182, 2003.

[96] O. Zhou, H. Shimoda, B. Gao, S. Oh, L. Fleming, and G. Yue, "Materials science of carbon nanotubes: fabrication, integration, and properties of macroscopic structures of carbon nanotubes," Accounts of Chemical Research, vol. 35, no. 12, pp. 1045-1053, 2002.

[97] M. Xu, Q. Huang, Q. Chen, P. Guo, and Z. Sun, "Synthesis and characterization of octadecylamine grafted multi-walled carbon nanotubes," Chemical Physics Letters, vol. 375, no. 5-6, pp. 598-604, 2003.

[98] S. Kishinevsky, S. I. Nikitenko, D. M. Pickup, E. R. H. Van-Eck, and A. Gedanken, "Catalytic transformation of carbon black to carbon nanotubes," Chemistry of Materials, vol. 14, no. 11, pp. 4498-4501, 2002.

[99] C. S. Johnson Jr., "Diffusion ordered nuclear magnetic resonance spectroscopy: principles and applications," Progress in Nuclear Magnetic Resonance Spectroscopy, vol. 34, no. 3-4, pp. 203-256, 1999.

[100] J. J. Castillo, M. H. Torres, D. R. Molina et al., "Monitoring the functionalization of single-walled carbon nanotubes with chitosan and folic acid by two-dimensional diffusion-ordered NMR spectroscopy," Carbon, vol. 50, no. 8, pp. 2691-2697, 2012. 
[101] A. Clementi, M. C. Aversa, C. Corsaro et al., "Synthesis and characterization of a colloidal novel folic acid- $\beta$-cyclodextrin conjugate for targeted drug delivery," Journal of Inclusion Phenomena and Macrocyclic Chemistry, vol. 69, no. 3-4, pp. 321325, 2011.

[102] S. Chen, S. Hu, E. F. Smith et al., "Aqueous cationic, anionic and non-ionic multi-walled carbon nanotubes, functionalised with minimal framework damage, for biomedical application," Biomaterials, vol. 35, no. 17, pp. 4729-4738, 2014.

[103] J. C. Bear, P. D. McNaughter, K. Jurkschat et al., "Synthesis and characterization of carbon nanotubes covalently functionalized with amphiphilic polymer coated superparamagnetic nanocrystals," Journal of Colloid and Interface Science, vol. 383, no. 1, pp. 110-117, 2012.

[104] D. K. Singh, P. K. Iyer, and P. K. Giri, "Optical signature of structural defects in single walled and muitiwalled carbon nanotubes," Journal of Nanoscience and Nanotechnology, vol. 9, no. 9, pp. 5396-5401, 2009.

[105] A. A. Bhirde, S. Patel, A. A. Sousa et al., "Distribution and clearance of PEG-single-walled carbon nanotube cancer drug delivery vehicles in mice," Nanomedicine, vol. 5, no. 10, pp. 15351546, 2010.

[106] K. Werengowska-Ciećwierz, M. Wiśniewski, A. P. Terzyk et al., "Nanotube-mediated efficiency of cisplatin anticancer therapy," Carbon, vol. 70, pp. 46-58, 2014.

[107] A. V. Crewe, J. Wall, and J. Lanomore, "Visibility of single atoms," Science, vol. 168, no. 3937, pp. 1338-1340, 1970.

[108] T. Muthukumar, S. Prabhavathi, M. Chamundeeswari, and T. P. Sastry, "Bio-modified carbon nanoparticles loaded with methotrexate possible carrier for anticancer drug delivery," Materials Science and Engineering C, vol. 36, pp. 14-19, 2014.

[109] C. Ge, J. Du, L. Zhao et al., "Binding of blood proteins to carbon nanotubes reduces cytotoxicity," Proceedings of the National Academy of Sciences of the United States of America, vol. 108, no. 41, pp. 16968-16973, 2011.

[110] K. Sattler, "Scanning tunneling microscopy of carbon nanotubes and nanocones," Carbon, vol. 33, no. 7, pp. 915-920, 1995.

[111] A. Bachmatiuk, F. Börrnert, F. Schäffel et al., "The formation of stacked-cup carbon nanotubes using chemical vapor deposition from ethanol over silica," Carbon, vol. 48, no. 11, pp. 3175-3181, 2010.

[112] M. C. Paiva, W. Xu, M. Fernanda Proença, R. M. Novais, E. Lægsgaard, and F. Besenbacher, "Unzipping of functionalized multiwall carbon nanotubes induced by STM," Nano Letters, vol. 10, no. 5, pp. 1764-1768, 2010.

[113] H. Lin, J. Lagoute, V. Repain et al., "Coupled study by TEM/EELS and STM/STS of electronic properties of C- and CN $x$-nanotubes," Comptes Rendus Physique, vol. 12, no. 9-10, pp. 909-920, 2011.

[114] H. Wu, G. Liu, Y. Zhuang et al., "The behavior after intravenous injection in mice of multiwalled carbon nanotube / $\mathrm{Fe}_{3} \mathrm{O}_{4}$ hybrid MRI contrast agents," Biomaterials, vol. 32, no. 21, pp. 4867-4876, 2011.

[115] G. Wei, C. Pan, J. Reichert, and K. D. Jandt, "Controlled assembly of protein-protected gold nanoparticles on noncovalent functionalized carbon nanotubes," Carbon, vol. 48, no. 3, pp. 645-653, 2010.

[116] C. C. Ciobotaru, C. M. Damian, S. Polosan, E. Matei, and H. Iovu, "Covalent functionalization of single walled carbon nanotubes with doxorubicin for controlled drug delivery systems," Digest Journal of Nanomaterials and Biostructures, vol. 9, no. 1, pp. 413-422, 2014.
[117] A. K. Jain, V. Dubey, N. K. Mehra et al., "Carbohydrateconjugated multiwalled carbon nanotubes: development and characterization," Nanomedicine: Nanotechnology, Biology and Medicine, vol. 5, no. 4, pp. 432-442, 2009.

[118] H. Mi, X. Zhang, Y. Xu, and F. Xiao, "Synthesis, characterization and electrochemical behavior of polypyrrole/carbon nanotube composites using organometallic-functionalized carbon nanotubes," Applied Surface Science, vol. 256, no. 7, pp. 2284-2288, 2010.

[119] C. Zhang, J. Sui, J. Li, Y. Tang, and W. Cai, "Efficient removal of heavy metal ions by thiol-functionalized superparamagnetic carbon nanotubes," Chemical Engineering Journal, vol. 210, pp. 45-52, 2012.

[120] E. Salehi, S. S. Madaeni, L. Rajabi et al., "Novel chitosan/poly(vinyl) alcohol thin adsorptive membranes modified with amino functionalized multi-walled carbon nanotubes for $\mathrm{Cu}(\mathrm{II})$ removal from water: preparation, characterization, adsorption kinetics and thermodynamics," Separation and Purification Technology, vol. 89, pp. 309-319, 2012.

[121] S. Y. Sawant, R. S. Somani, H. C. Bajaj, and S. S. Sharma, "A dechlorination pathway for synthesis of horn shaped carbon nanotubes and its adsorption properties for $\mathrm{CO}_{2}, \mathrm{CH}_{4}, \mathrm{CO}$ and $\mathrm{N}_{2}$," Journal of Hazardous Materials, vol. 227-228, pp. 317-326, 2012.

[122] A. Reyhani, S. Z. Mortazavi, S. Mirershadi, A. N. Golikand, and A. Z. Moshfegh, " $\mathrm{H}_{2}$ adsorption mechanism in $\mathrm{Mg}$ modified multi-walled carbon nanotubes for hydrogen storage," International Journal of Hydrogen Energy, vol. 37, no. 2, pp. 1919-1926, 2012.

[123] P. R. Chang, P. Zheng, B. Liu, D. P. Anderson, J. Yu, and X. Ma, "Characterization of magnetic soluble starch-functionalized carbon nanotubes and its application for the adsorption of the dyes," Journal of Hazardous Materials, vol. 186, no. 2-3, pp. 21442150, 2011.

[124] S. Brunauer, P. H. Emmett, and E. Teller, "Adsorption of gases in multimolecular layers," Journal of the American Chemical Society, vol. 60, no. 2, pp. 309-319, 1938.

[125] B. C. Lippens and J. H. de Boer, "Studies on pore systems in catalysts: v. The $t$ method," Journal of Catalysis, vol. 4, no. 3, pp. 319-323, 1965.

[126] R. R. N. Marques, B. F. Machado, J. L. Faria, and A. M. T. Silva, "Controlled generation of oxygen functionalities on the surface of single-walled carbon nanotubes by $\mathrm{HNO}_{3}$ hydrothermal oxidation," Carbon, vol. 48, no. 5, pp. 1515-1523, 2010.

[127] N. Chigumbu, S. Iyuke, V. Pillay, and S. Ndlovu, "In vitro evaluation of the physicochemical effects of drug loaded carbon nanotubes on toxicity," Journal of Nanomedicine and Nanotechnology, vol. 3, no. 4, pp. 1-7, 2012.

[128] C. Gaillard, M. Duval, H. Dumortier, and A. Bianco, "Carbon nanotube-coupled cell adhesion peptides are nonimmunogenic: a promising step toward new biomedical devices," Journal of Peptide Science, vol. 17, no. 2, pp. 139-142, 2011.

[129] W. Shao, A. Paul, B. Zhao, C. Lee, L. Rodes, and S. Prakash, "Carbon nanotube lipid drug approach for targeted delivery of a chemotherapy drug in a human breast cancer xenograft animal model," Biomaterials, vol. 34, pp. 10109-10119, 2013.

[130] Z. Cao, R. Tong, A. Mishra et al., "Reversible cell-specific drug delivery with aptamer-functionalized liposomes," Angewandte Chemie, vol. 48, no. 35, pp. 6494-6498, 2009. 
[131] N. J. Wheate, S. Walker, G. E. Craig, and R. Oun, "The status of platinum anticancer drugs in the clinic and in clinical trials," Dalton Transactions, vol. 39, no. 35, pp. 8113-8127, 2010.

[132] A. A. Bhirde, V. Patel, J. Gavard et al., "Targeted killing of cancer cells in vivo and in vitro with EGF-directed carbon nanotubebased drug delivery," ACS Nano, vol. 3, no. 2, pp. 307-316, 2009. 

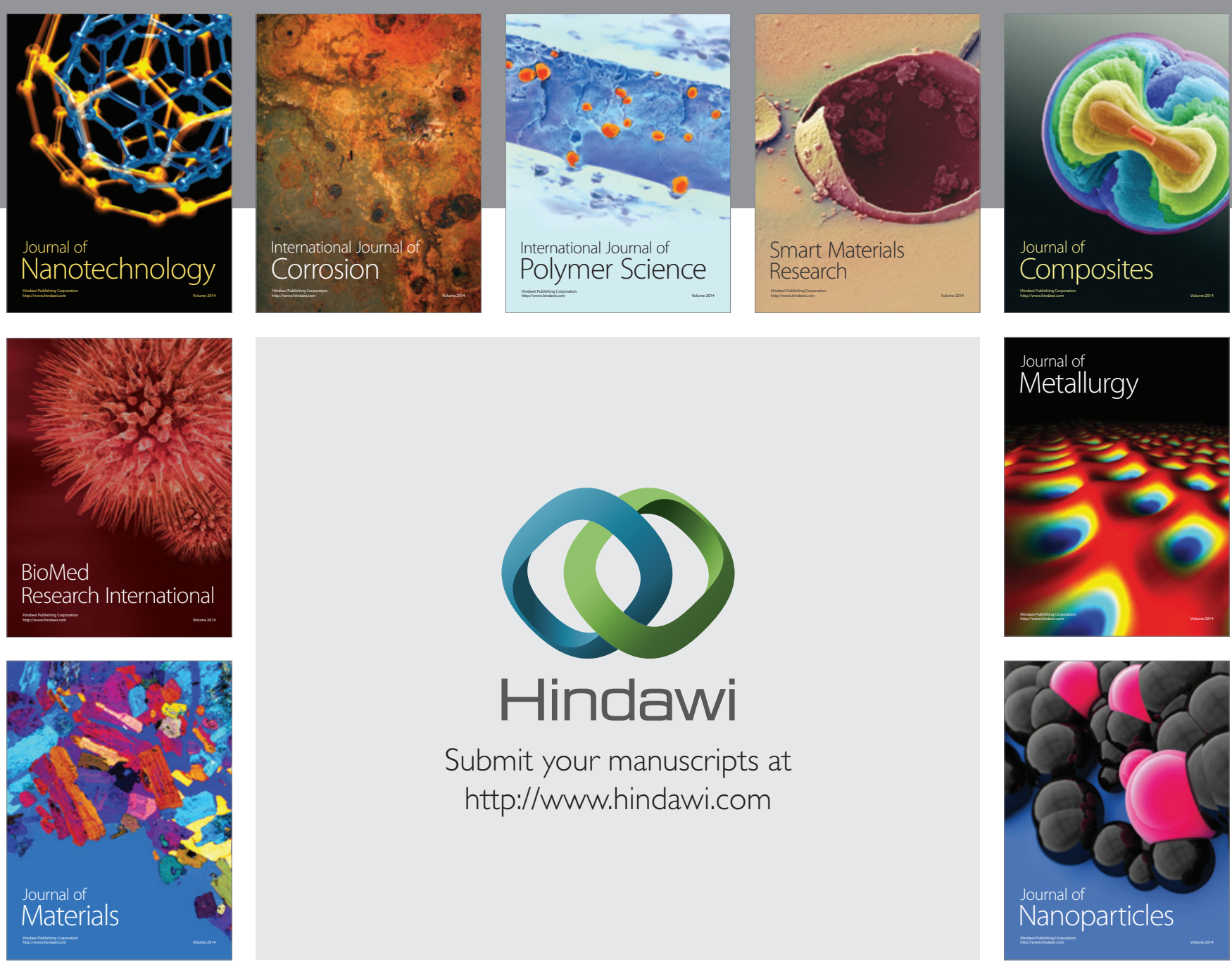

Submit your manuscripts at http://www.hindawi.com
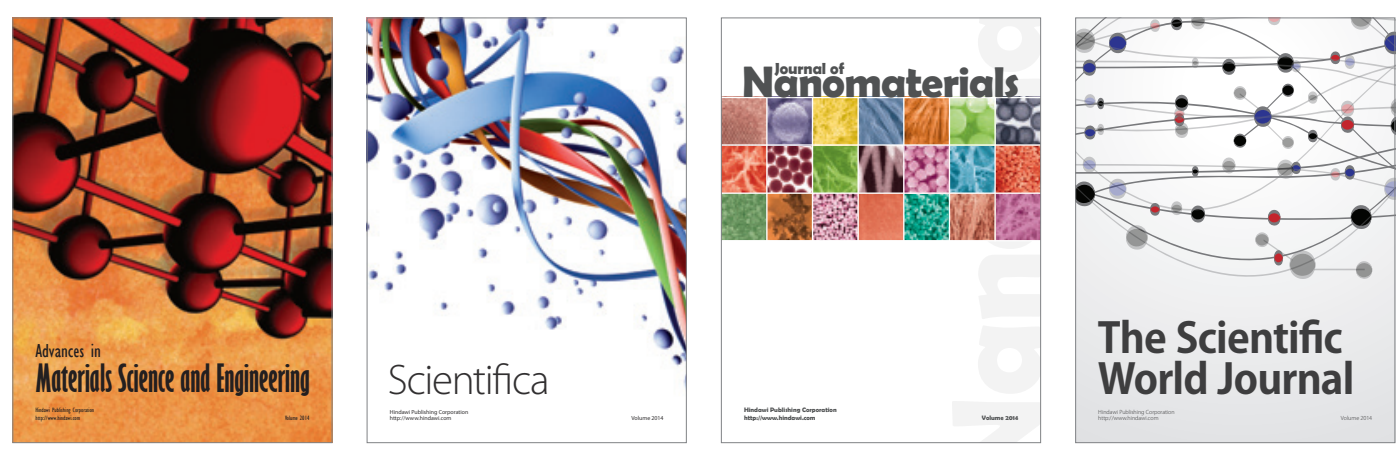

\section{The Scientific World Journal}
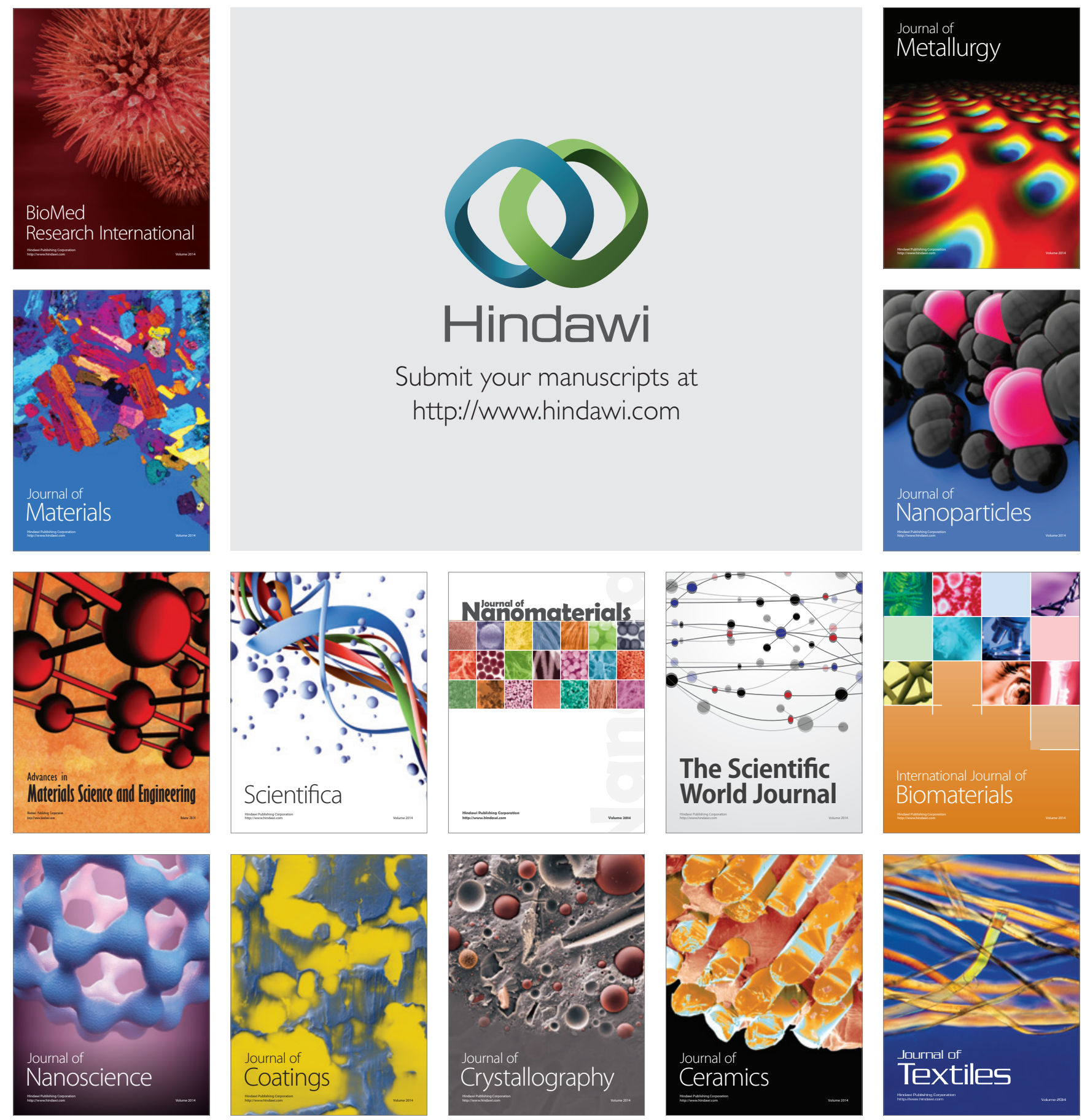